San Jose State University

SJSU ScholarWorks

Master's Theses

Master's Theses and Graduate Research

Summer 2016

\title{
Cux2-Positive Radial Glial Cells Generate Diverse Subtypes of Neocortical Projection Neurons and Macroglia
}

Ton Dan Nguyen

San Jose State University

Follow this and additional works at: https://scholarworks.sjsu.edu/etd_theses

\section{Recommended Citation}

Nguyen, Ton Dan, "Cux2-Positive Radial Glial Cells Generate Diverse Subtypes of Neocortical Projection Neurons and Macroglia" (2016). Master's Theses. 4732.

DOI: https://doi.org/10.31979/etd.v8xn-b84g

https://scholarworks.sjsu.edu/etd_theses/4732

This Thesis is brought to you for free and open access by the Master's Theses and Graduate Research at SJSU ScholarWorks. It has been accepted for inclusion in Master's Theses by an authorized administrator of SJSU ScholarWorks. For more information, please contact scholarworks@sjsu.edu. 


\author{
A Thesis \\ Presented to \\ The Faculty of Department of Biological Studies \\ San José State University \\ In Partial Fulfillment \\ of the Requirements for the Degree \\ Master of Science
}

by

Ton Dan Nguyen

August 2016 
(C) 2016

Ton Dan Nguyen

ALL RIGHTS RESERVED 
The Designated Thesis Committee Approves the Thesis Titled

\section{CUX2-POSITIVE RADIAL GLIAL CELLS GENERATE DIVERSE SUBTYPES OF NEOCORTICAL PROJECTION NEURONS AND MACROGLIA}

By

Ton Dan Nguyen

APPROVED FOR THE DEPARTMENT OF BIOLOGICAL SCIENCES SAN JOSÉ STATE UNIVERSITY

August 2016

Dr. Tzvia Abramson, Committee Chair

Dr. Katherine Wilkinson

Dr. Bin Chen
Department of Biological Sciences, SJSU

Department of Biological Sciences, SJSU

Department of MCD Biology, UCSC 


\begin{abstract}
The mammalian neocortex is 6-layered structure that develops in an "inside-out" manner, with cells of the deep layers (Layers 5-6) born first. Cells of the superficial outer layers (Layers 2-4) are generated subsequently and must migrate past older born cells to their final laminar position. Pioneering transplant studies suggested a progressive lineage restriction model, which posits that early neural stem cells (or radial glial cells, RGCs) are multipotent and sequentially generate different types of cortical neurons based on birthdate. Recently published work from Franco et al. (2012) argues against this paradigm, and proposes the existence of a subclass of neural stem cells, fated from an early embryonic age to produce exclusively upper-layer neurons. They contend that at mouse embryonic day 10.5 (E10.5), when neocortical genesis is just beginning, an RGC subpopulation marked by expression of genetic transcription factor cut-like homeobox 2 (Cux2) is fated to produce exclusively upper layer (L2-4) cells. Cells not expressing Cux2 are fated to become deep layer (L5-6). We recently published work testing this model using Cre-mediated recombination. Our experiments demonstrated that both clonal and population levels of $\mathrm{Cux} 2^{+}$and Fezf $2^{+}$RGCs produce progeny that are multipotent and able to generate neurons, astrocytes, and oligodendrocytes. Here, we extend our lab's previous work of the Cux2-positive and Fezf2-positive RGC lineages and find that E10.5 neocortical progenitors are able to generate diverse neuronal subtypes located throughout layers 2-6 as well as macroglia. Collectively, we find that Cux2-positive RGCs development does not differ from the progressive lineage restriction theory, and does not support the cell-intrinsic theory postulated by Franco et al. (2012).
\end{abstract}




\section{ACKNOWLEDGEMENTS}

\section{Personal}

This work would have not been possible without significant contributions of many people. I want to thank Dr. Matthew Eckler, the original investigator who wanted to pursue this project. His knowledge and meticulousness was invaluable in explaining the problem and keeping this project focused. Dr. Bin Chen helped with scientific training and kept this experiment on point, and Dr. William McKenna helped immensely with his technical knowledge and troubleshooting skills. Furthermore, I would like to thank Dr. Tzvia Abramson for all her support and patience throughout this long endeavor, as well as Dr. Katherine Wilkinson for her input and help with editing this thesis.

\section{Official Manuscript}

We thank Dr. Arturo Alvarez-Buylla for advice on experiments. We thank Drs. Chris Doe, Songhai Shi, Susan McConnell, Pushkar Joshi, and Jake Kirkland for critical reading and advice on the manuscript. We thank Dr. Ben Abrams and the UCSC Microscopy Center for help with image acquisition, and Dr. Tzvia Abramson (San Jose State University) for her support of this research. This work was funded by grant R01MH094589 from the National Institutes of Health (to B.C.), New Faculty Award RN1-00530-1 from the California Institute of Regenerative Medicine (CIRM; to B.C.), Bridges Grant TB1-01195 from CIRM to San Jose State University (to T.D.N.), Training Grant TG2-001157 from CIRM (to W.L.M. and C.G.) and grants R01MH049428 and R01NS34661 from the National Institutes of Health (to J.L.R.R.) 


\section{TABLE OF CONTENTS}

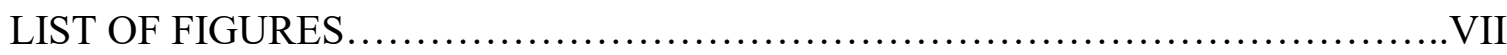

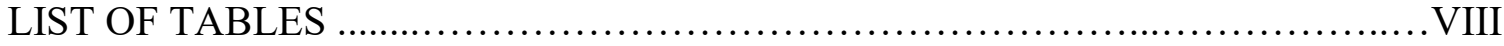

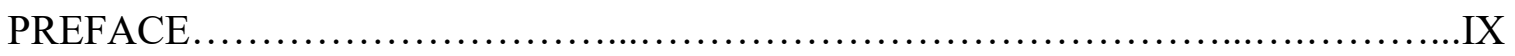

CHAPTER I

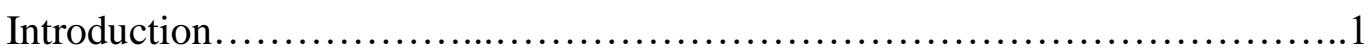

The Intrinsic Fate-Restricted Model.......................................9

Challenging the Fate-Restricted Model...................................12

\section{CHAPTER II}

Cux2-Positive Radial Glial Cells Generate Diverse Subtypes of Neocortical

Projection Neurons and Macroglia.......................................18

\section{CHAPTER III}

Conclusion......................................................46

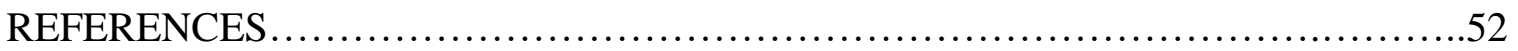




\section{LIST OF FIGURES}

Figure I. Neocortical projection neurons are generated in an "inside-out" fashion by diverse progenitor types in the VZ and SVZ. (Greig et al. 2013)..............4

Figure II. Expression of Cux2 in a subset of RGCs suggests multiple progenitor types. (Franco et al. 2012)............................................. 11

Figure III. RGCs of the Cux2 lineage are fated to generate upper layer neurons.

(Franco et al. 2012).

Figure IV. CUX2 ${ }^{+}$Cells in VZ/SVZ Are Migrating Interneurons and Cux2-

Cre/CreER ${ }^{T 2}$-Labeled RGCs Generate Both Deep- and Upper-Layer

Projection Neurons. (Guo et al. 2013). 16

Figure 1. Individual E10.5 Cux2 ${ }^{+} \mathrm{RGCs}$ generate cortical projection neurons and

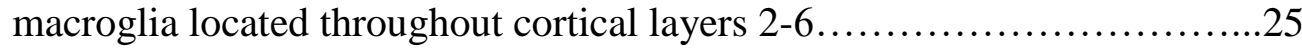

Figure 2. $\mathrm{Cux} 2^{+} \mathrm{RGCs}$ generate diverse, molecularly defined subtypes of cortical projection neurons and macroglia.

Figure 3. Similar to early Cux $2^{+}$RGCs, E10.5 Fezf2 ${ }^{+}$RGCs generate diverse subtypes of cortical projection neurons and glia................................ 31

Figure 4. Retrograde labeling of the $\mathrm{Cux}^{+}$and Fezf $2^{+}$lineages.....................

Figure S1. Related to Figure 1. The Cux2-Cre allele does not report the origin of neocortical projection neurons.

Figure S2. Related to Figure 1. Images from the Allen Brain Atlas show that tdTomato ${ }^{+}$

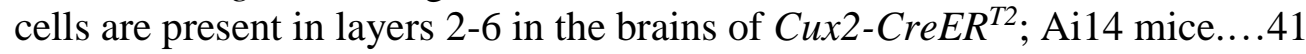




\section{LIST OF TABLES}

Table S1. Summary of fully reconstructed $\mathrm{Cux} 2^{+}$and Fezf2 ${ }^{+}$clones analyzed in this study....................................................... 42 


\section{PREFACE}

This thesis is divided into three chapters. Due to the unique nature of the problem presented, additional background information is required. Chapter I will introduce the progressive lineage restriction theory, which this study concerns, as well as a primer on the lineage tracing strategy employed. It will also provide a summary on the challenge and rebuttal to this theory, specifically the Müller Lab's cell fate-restricted theory presented by Franco et al. (2012) and the Chen Lab's original publication from Guo et al. (2013). This will establish precedent for Chapter II, which will present the manuscript titled Cux2-Positive Radial Glial Cells Generate Diverse Subtypes of Neocortical Projection Neurons and Macroglia published concurrently with the Müller Lab's Matters Arising Lineage Tracing Using Cux2 Cre and CreER ${ }^{T 2}$ written by Gil-Sanz et al. published in the May 20, 2015 edition of Neuron. Additionally, the salient ideas presented in the paper will the reiterated in Chapter III concluding remarks and future directions. 



\section{CHAPTER I}

\section{Introduction - The Progressive Lineage Restriction Theory}

The mammalian cortex is comprised of billions of cells and hundreds of neuronal subtypes that must be generated in a precise and controlled manner. Defects in proper neurodevelopment have been implicated in autism spectrum disorder (ASD), attention deficit-hyperactive disorder (ADHD), and schizophrenia (Stoodley, 2015; Selemon and Zecevic, 2015). Therefore, a comprehensive understanding of brain development is critical to understanding many complicated neurological ailments.

Mammalian neurodevelopment is a complex process that is regulated by specific spatiotemporal cues, morphogenic gradients, and a multitude of collaborating or competing transcription factors (Greig et al., 2012; Molyneaux et al., 2007). During embryogenesis, cortical development initiates with the formation of the preplate at the anterior-most end of the neural tube. The preplate then bifurcates into two layers, the marginal zone (future layer I) and subplate. The superficial marginal zone contains CajalRetzius cells that secrete reelin, a protein necessary for proper neuronal migration and development (Hack et al., 2002; Kumamoto and Hanashima, 2014).

Neuroepithelial (NE) cells are a single layer of pseudostratified cells originating from the ectodermal germ layer. At the anterior neural tube, these neural stem cell precursors will develop into the cerebrum. NE cells give rise to radial glial cells (RGCs), the neural stem cells of the developing cortex. Neurons born from RGCs migrate from the ventricular zone (VZ), adjacent to the lateral ventricle (LV), and form the cortical plate $(\mathrm{CP})$ which will give rise to layers 2-6 of the cerebral cortex. 
The neocortex is a unique feature of the mammalian central nervous system that is associated with the highest-level cognition (Aggelopoulos, 2015), planned motor movement (Kawai et al., 2015), and complex sensory processing (Jang, 2013; Pleger and Villringer, 2013). Our study focuses on the lineages of RGCs, which are the ultimate source of cortical excitatory neurons and some astrocytes and oligodendrocytes of the mature cerebral cortex.

Cortical development commences in mice at approximately embryonic day 10.5 (E10.5) with rapid RGC proliferation. These cells mostly divide symmetrically to generate two RGCs and expand the progenitor pool (DeBoer et al., 2013). To produce postmitotic neurons that can no longer divide, RGCs can divide asymmetrically by generating one self-renewing RGC and one mature neuron (Bultje et al., 2009). Much more commonly, one intermediate progenitor cell (IPC) is produced in lieu of a neuron (Weissman et al., 2003). There are multiple classes of intermediate progenitors such as basal progenitors, shorter nuclear precursors, and outer radial glial cells. Together, IPCs allow rapid cellular expansion and proliferation through additional rounds of division and differentiation (Greig et al., 2013). In fact, outer RGCs are dramatically increased in human fetal brains, allowing the rapid generation of exponentially more cells relative to the mouse brain. These two strategies of symmetric and asymmetric division allow for rapid growth during neurogenesis. Our study focuses on the clonal-level, which is an individual RGC and all of its subsequent progeny.

RGCs also serve an important function that allows for longitudinal, or radial, neuronal migration (McConnell, 1995) — outwards from the VZ like rays of a sun. These 
cells have soma which normally reside in the $\mathrm{VZ}$ and produce long processes that connect both the apical (LV) and basal (pial) surfaces of the developing cortex. These processes provide the scaffold necessary for newborn neurons to migrate to their final laminar position (Tan and Breen, 1993).

The mammalian neocortex is a six-layered structure that develops in an "insideout" manner (Fig I), with deep layer neurons generated before superficial layer neurons (Greig et al., 2012; DeBoer et al., 2013). The Layer 6 neurons are generated first and marked postnatally by the expression of transcription factor Tbr1 (T-box brain 1). Subsequently generated neurons must migrate past the earlier-born neurons to reach their final laminar position. For example, Layer 5 neurons, postnatally marked by increased Ctip2 (also called BCL11B/B-cell lymphoma 11B) expression, migrate past Layer 6 neurons. Superficial neurons (Layers 2-4), identified by Cux 1 and Cux2 (Cut-like homeobox 1 and 2) expression in the mature brain, migrate past both Layers 5 and 6 (Molyneaux et al., 2007).

The inside-out pattern of cortical neurogenesis was first illustrated using birthdating experiments (Angevine et al., 1961). Using a radiolabeled thymidine tracer that incorporates into the DNA after injection, there were clearly defined layers corresponding to when the injection was administered. For example, an injection during early corticogenesis labels only deep layer 6 cells. Subsequent injections would correspondingly label layer 5 , layer 4 , and layer $2 / 3$ in that order.

A progressive lineage restriction model was proposed to explain the lineage relationships between cortical progenitors and excitatory neurons. Transplantation of 


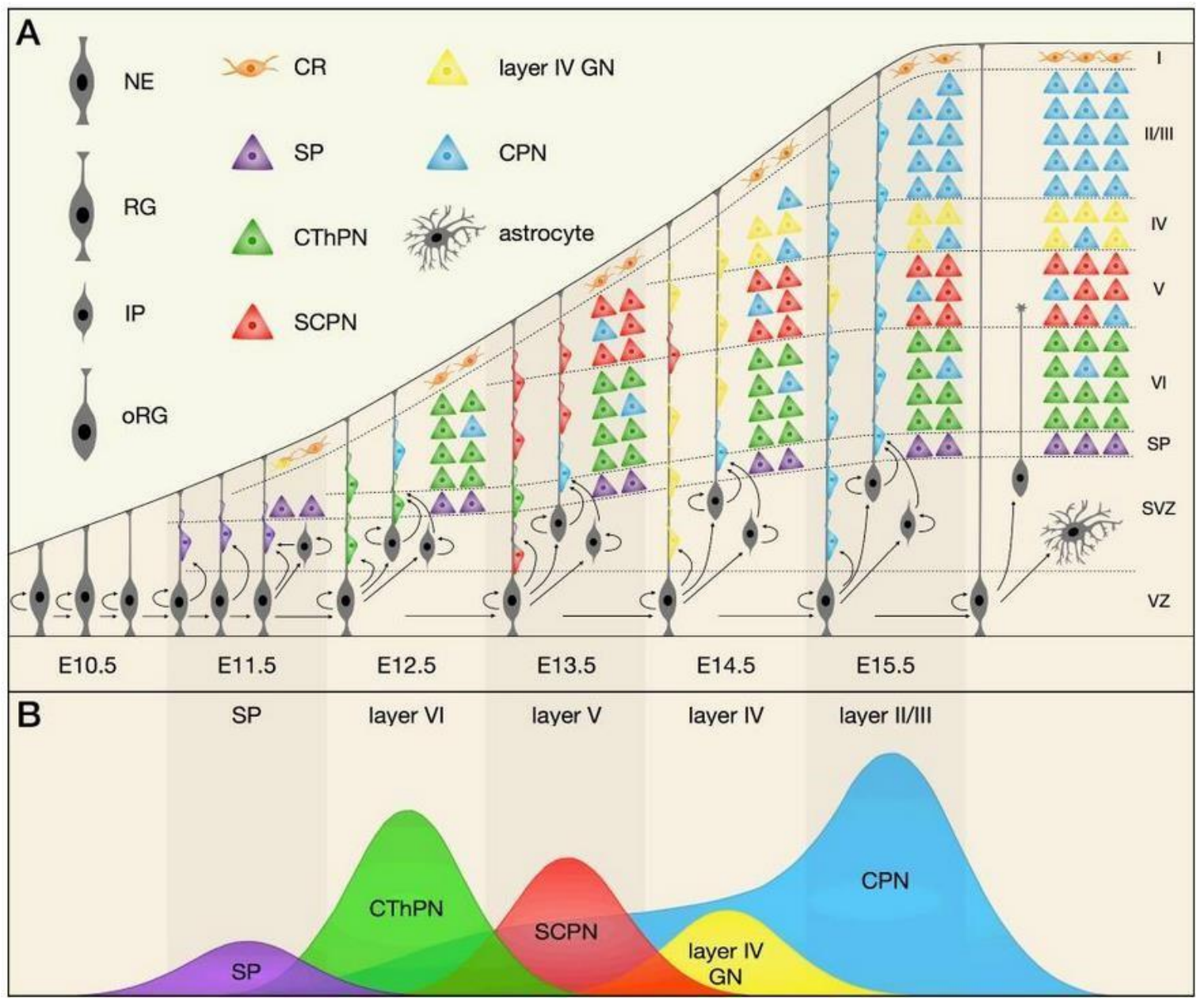

Figure I. Neocortical projection neurons are generated in an "inside-out" fashion by diverse progenitor types in the VZ and SVZ. This schematic depicts the sequential generation of neocortical projection neuron subtypes and their migration to appropriate layers over the course of mouse embryonic development. (a) Radial glia (RG) in the ventricular zone (VZ) begin to produce projection neurons around E11.5. At the same time, RG generate intermediate progenitors (IP) and outer radial glia (oRG), which establish the subventricular zone (SVZ) and act as transit-amplifying cells to increase neuronal production. After neurogenesis is complete, neural progenitors transition to a gliogenic mode, generating astrocytes and oligodendrocytes. Cajal-Retzius (CR) cells primarily migrate into neocortical layer I from non-cortical locations, while other projection neurons are born in the neocortical VZ / SVZ and migrate along radial glial processes to reach their final laminar destinations. (b) Distinct projection neuron subtypes are born in sequential waves over the course of neurogenesis. The peak birth of subplate (SP) neurons occurs around embryonic day (E) 11.5, with the peak birth of corticothalamic projection neurons (CThPN) and subcerebral projection neurons (SCPN) occurring at E12.5 and E13.5, respectively. Layer IV granular neurons (GN) are born around E14.5. Some callosal projection neurons (CPN) are born starting at E12.5, and those CPN born concurrently with CThPN and SCPN also migrate to deep layers. Most CPN are born between E14.5 and E16.5, and these late-born CPN migrate to superficial cortical layers. Peak sizes are proportional to the approximate number of neurons of each subtype born on each day. NE, neuroepithelial cell; WM, white matter.

Reprinted with permission from Greig, L.C., Woodworth, M.B., Galazo, M.J., Padmanabhan, H., Macklis, J.D. Molecular logic of neocortical projection neuron specification development and diversity. 2013. Nat Rev Neurosci 14, 755-769 
early-stage RGCs into a late-stage developing cortex will ectopically generate cells of all cortical layers (McConnell, 1985), while late-stage RGCs are lineage-restricted to generate later-born, upper-layer neurons. These results suggest that RGC potential is gradually restricted in a time-dependent manner (Fig I). At about embryonic day 10.5 (E10.5) in mice, RGCs can generate diverse cell types that span all neocortical layers. However, this ability is gradually restricted. Neurogenesis continues into adulthood, albeit at a comparatively limited capacity. Adult-born cells are generally restricted to the dentate gyrus of the hippocampus and olfactory bulb interneurons (Fuentealba et al., 2015; Lledo et al., 2008; Young et al., 2007)

The lineage restriction theory also pertains to neuronal subtype identity. Generally speaking, cells within specific cortical layers have conserved functions (Fig. I). For example, Layer 6 neurons have axonal projections that extend to the thalamus, and thus, are called corticothalamic projection neurons. Layer 5 neurons connecting to the spinal cord are called corticospinal projection neurons. Collectively, deep layer cells with subcerebral axonal targets are sometimes referred to as corticofugal projection neurons. On the other hand, cells residing within the upper layers, especially those of Layer $2 / 3$, project axons to other cortical areas, including the contralateral hemisphere (callosal projection neurons) (Molyneaux et al., 2007). However, it should be pointed out that the same types of cortical projection neurons can be located in different cortical layers, particularly the callosal projection neurons.

Additionally, not all neuronal subtypes that culminate in the neocortex originate in the cortical VZ. While this study focuses primarily on excitatory neurons rising from 
RGCs in dorsal VZ, inhibitory interneurons originate primarily from the VZ of medial and caudal ganglionic eminences (Anderson et al., 1997; Marin and Müller, 2014). Whereas RGC-born excitatory neurons migrate radially, cortical interneurons migrate tangentially, almost circumferentially, into the neocortex (Sultan et al., 2014) to occupy the same neighborhood as their excitatory brethren (Markram et al., 2004). This generates an interwoven mesh of excitatory and inhibitory neurons within the cortex.

Interestingly, RGCs have been proposed to comprise the basic building block of the developed mammalian cortex (Yu et al., 2009; He et al., 2015), akin to the kidney's nephron or the eye's rods and cones. Daughter cells that arise from the same RGC have a higher rate of electrical coupling activity when compared to neighboring cells of indeterminate origin (He et al., 2015). Furthermore, the percentage of electric coupling increases through late embryogenesis into postnatal mice, suggesting involvement in the maturation of the cortex (Yu et al., 2009). Collectively, this has been termed the radial unit hypothesis (Rakic, 1971; Tan and Breen, 1993).

While the progressive lineage restriction theory can be applied broadly to the RGC population as a whole, it may not be precise enough. The neocortex is generated by the coordinated effort of many thousands of RGCs, and there may be subpopulations that are exceptions to this rule. To determine this, examination of individual RGCs and their progeny is required. Such RGC clones must be investigated carefully to determine their final laminar position and identity of the constituent neuronal progeny. 


\section{Lineage Tracing}

RGCs and their progeny can be lineage traced using a variety of methods. Some of the earliest methods were indirect, utilizing cell ablation techniques in order to determine what cell types are necessary and sufficient (Hicks and D'Amato, 1975). An early progenitor is destroyed and downstream effects such as absent or impaired organs were determined post facto. Later experiments utilized an injectable dye (DiI) that incorporates into the cell membrane. A traced cell and its progeny can be followed throughout development into maturity (Anderson et al., 1997). Recent techniques include in utero electroporation, injecting a plasmid or retroviral vector expressing green fluorescent protein (GFP) into the embryo (Nakahira et al., 2006). This vector can induce fluorescent protein expression in a subset of cells, labeling the progenitor cell as well as its progeny. However, these techniques are invasive and technically difficult to perform.

For our purposes, we utilize the genetic Cre-lox system. The Cre protein (causes recombination), first isolated from the $\mathrm{P} 1$ bacteriophage, can induce genetic rearrangement at specific and conserved sequences (Sternberg and Hamilton, 1981). Cre expression can be tied directly to a gene promoter and activated only upon concurrent promoter activity. It will then initiate genomic rearrangement by acting at conserved sequences called loxp sites. If a certain sequence contains flanking loxp sites, it is called "floxed." The orientation of the loxp site can also determine the type of recombination, which includes inversion, translocation, and deletion (Nagy, 2000). This overall strategy is sometimes termed site-specific recombination (Sauer and Henderson, 1988). 
Cre expression alone is insufficient to determine lineage tracing. It must be directly tied to the expression of a reporter that permanently labels the cell and all of its progeny. A common strategy utilizes the expression fluorescent reporters such as GFP or tdTomato (Fig. III A, E). RCE-GFP is an engineered variant of GFP which utilizes a cytomegalovirus enhancer linked to an enhanced GFP (Sato et al., 2000). This construct is placed downstream of a "stop" codon and Rosa26, a constitutively and ubiquitously expressed gene in all mice cells (Friedrich and Soriano, 1991). Therefore, in mice that contain both genetic sequences, promoter activation will drive Cre expression that excises the "stop" codon and allow reporter (such as RCE-GFP) expression. Furthermore, this is a permanent genetic recombination that persists in the affected cell and all of its progeny. For our experiments, we use an inducible form of Cre called $C r e E R^{T 2}$. It utilizes the Cre protein conjugated to an estrogen receptor $\left(E R^{T 2}\right)$. Estrogen is a steroidal hormone that can permeate the cell membrane, bind to $C r e E R^{T 2}$, and initiate its recombinase activity (Leone et al., 2003). The estrogen analogue tamoxifen (TM) is used, which is metabolically active for $24-48$ hours, and can recombine activated cells within that time window. The primary advantage of $C r e E R^{T 2}$ versus Cre is its temporal activation. Promoter activity may initiate production for the $C r e E R^{T 2}$ protein, but it remains inactive in the cytoplasm. Only upon TM injection and binding can it translocate into the nucleus and activate recombination.

In short, we utilize a genetic recombination strategy to conduct a lineage tracing study. With the exception of a single TM injection, this technique is minimally invasive. The caveat is that recombination is subject to probability, and which is dependent on the 
dosage of TM given, promoter activity, and construct efficiency (Lizen et al., 2015). A dosage may be given based on previous studies, or estimated indirectly through in situ hybridization from a consistent source, such as the Allen Brain Atlas. Ultimately, it must be done empirically by weighing mice, calculating dosage, and evaluating the results.

However, the Cre-lox system remains a robust tool that utilizes a promoteractivated Cre protein and can be used to selectively excise a floxed sequence, such as a "stop" codon. This excision will allow RCE-GFP expression in a subset of cells expressing the promoter. Furthermore, the temporal window for $C r e E R^{T 2}$ activation may be controlled via TM administration. This permits labeling a subset of RGCs at various developmental stages and following and their progeny to examine their final laminar position and molecular identity.

\section{The Intrinsic Fate-Restriction Model of Neocortical Development}

Recently published work proposes an alternate hypothesis to the progressive lineage restriction theory. Data generated by the Müller Lab at the Scripps Institute (Franco et al., 2012) suggested the intrinsic fate-restriction model of cortical development. This model postulates that shortly after the advent of RGCs from neuroepithelial cells (approximately E10.5 in mice), a subset of RGCs marked by Cux2 (cut-like homeobox 2) expression will give rise to exclusively superficial layer projection neurons (Layers 2-4).

In order to reach this conclusion, Franco et al. conducted a variety of experiments. First, they performed an in situ hybridization at E14.5 to show Cux2 expression at the ventricular zone (VZ) (Fig. II. B). This suggests that a subset of the RGCs within the VZ 
are $\mathrm{Cux} 2^{+}$during embryogenesis. This was complemented with another in situ at P7, after corticogenesis is mostly completed, revealing a dramatic increase in Cux 2 mRNA expression in the upper layers (Figure II. A). Then using a Cux2-Cre transgenic mouse crossed with an Ai9 tdTomato reporter, they show recombination at E14.5 (Fig. II. D) revealing neurons migrating from the $\mathrm{VZ}$ into the cortical plate. These cells then appear to predominantly populate the upper layers by P10 (Fig. II. C).

Further immunohistochemistry shows that E14.5 Cux2+ RGCs also express Pax6 (Paired box 6), a stem cell marker, nestin, an early neuronal marker, and Tbr2 (T-box brain 2), an IPC marker (Fig. I. E-G). YoYo1, a DNA stain, reveals mitotic spindle division perpendicular to the LV typical of RGCs undergoing symmetric division (Fig. II. H-I) (Noctor et al., 2008). These results collectively suggest that during development cortical VZ cells expressing Cux2 are RGCs that will generate upper layer neurons.

Within the same paper, further analysis was performed with an intention to further prove the Cux2+ RGCs were lineage-restricted to generate upper-layer neurons. In utero electroporation was done at E12.5 using a FLEx plasmid that can switch expression from tdTomato to eGFP upon Cre activation (Fig III. A). Using Cux2-Cre mediated recombination, they reported a high percentage of Cux2-positive eGFP neurons end up in upper layers at P10. Conversely, the majority of Cux2-negative tdTomato neurons remained within the deeper layers (Fig. III. B-D).

A comparison was then done using the tamoxifen-inducible $C r e E R^{T 2}$ system between Cux2 and nestin, a general transcription factor activated in post-mitotic cells of the neuronal lineage (Fig. III. E). Using an Ai9 tdTomato reporter, tamoxifen injection in 

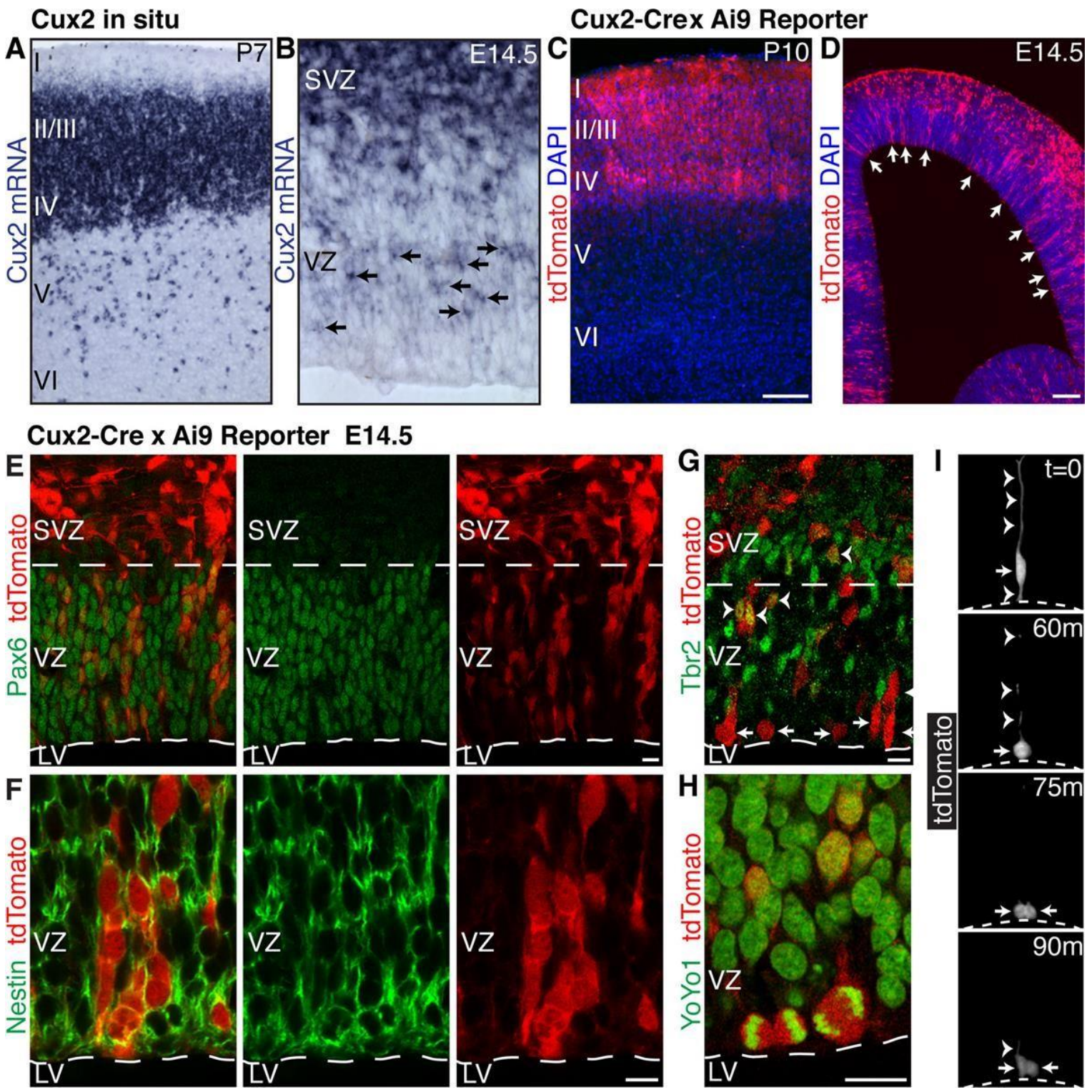

Fig II. Expression of Cux2 in a subset of RGCs suggest multiple progenitor types. (A and B) In situ hybridization shows Cux2 mRNA at P7 (A) and E14.5 (B). Arrows indicate expression in a subset of ventricular zone cells. (C and D) Cumulative fate mapping of the Cux2 lineage in Cux2-Cre;Ai9 mice at P10 (C) and E14.5 (D). Arrows indicate recombination in a subset of ventricular zone cells. (E and F) Recombination in $\operatorname{Pax6}^{+}(\mathrm{E})$ and nestin ${ }^{+}(\mathrm{F})$ RGCs. (G) Recombination in Tbr2 ${ }^{+}$ intermediate progenitors (arrowheads) and Tbr2- RGCs (arrows) in the ventricular zone. (H) Recombined mitotic cells dividing at the ventricular surface. (I) Live imaging of a slice culture from a Cux2-Cre;Ai9 embryo

From Franco, S.J., Gil-Sanz, C., Martinez-Garay, I., Espinosa, A., Harkins-Perry, S.R., Ramos, C., Müller, U. Faterestricted neural progenitors in the mammalian cerebral cortex. Science. 10 August 2012. 337(6095): 746-749. Reprinted with permission from AAMS. 
Cux2-CreER ${ }^{T 2}$ at E10.5 resulted in upper layer neuronal fate (Fig. III. G). This was contrasted with Nestin-CreER ${ }^{T 2}$, which resulted in a dispersed laminar fate occupying all cortical layers (Fig. III. F). They reported a $90 \%$ upper to $10 \%$ deep layer laminar distribution for Cux2-positive E10.5 RGCs, compared to approximately 55\% upper to $45 \%$ deep layer seen with the Nestin-postive RGCs, a neuronal control.

Figures II and III form the crux of the Müller lab's fate-restricted theory. Altogether, these experiments suggest that Cux2 expression in RGCs at the onset of corticogenesis will produce neurons that are fated to generate only upper layer neurons. If true, this novel theory would constitute a drastic paradigm shift in the understanding cortical development. Rather than regulated by specific spatiotemporal cues, a subset of cells can be activated at a nascent stage into a specific and predetermined role. This would have displaced much of the current understanding cortical development.

However, these ideas were initially challenged in Guo et al. 2013 (explained in greater detail in the next section). The bulk of contention to Franco et al. 2012 will be addressed in this thesis, and a summary overview to these arguments will be re-examined in greater detail in Chapter III. Specifically, Fig II and Fig III will be scrutinized.

\section{Guo et al. 2013 Initial Challenge to the Fate-Restricted Model of Development}

The Chen lab independently tested the existence of intrinsic lineage-restricted RGCs using another transcription factor expressed in RGCs, Fezf2 (Forebrain zinc-finger protein 2) (Guo et al., 2013). Fezf2 is a transcription factor expressed in the dorsal lateral ventricle of the developing embryo (Chen et al., 2005a; Hirata-Fukae and Hirata, 2014; McKenna et al., 2011). It is also expressed predominantly within layers 5 and 6 of the 


\section{A Temporal Cux2 Fate Mapping by In Utero Electroporation}

C $\beta$ A-FLEx Plasmid

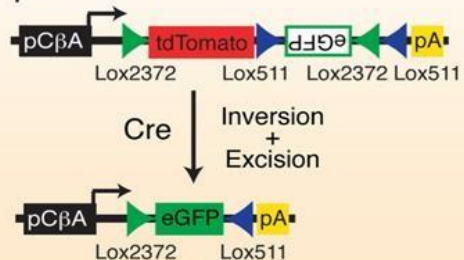

In Utero Electroporation

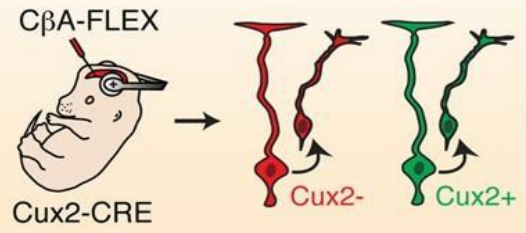

Cux2-Cre $\leadsto$ C $\beta$ A-FLEX at E12.5
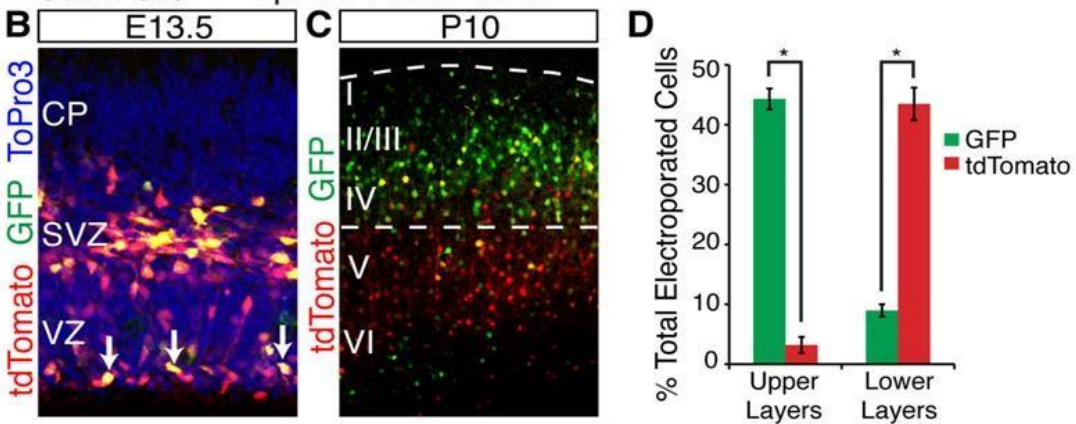

\section{E}

Temporal Cux2 Fate Mapping by Tamoxifen Induction

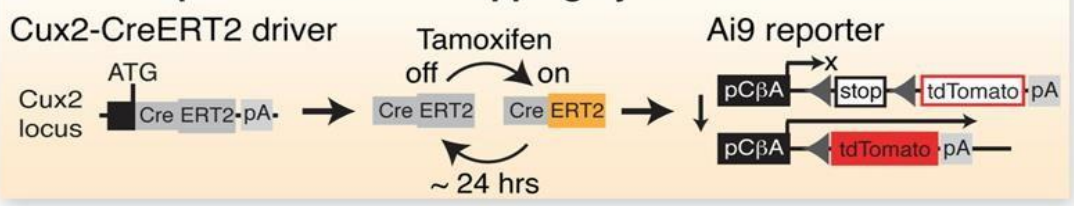

Tamoxifen at E10.5, Analysis at P10
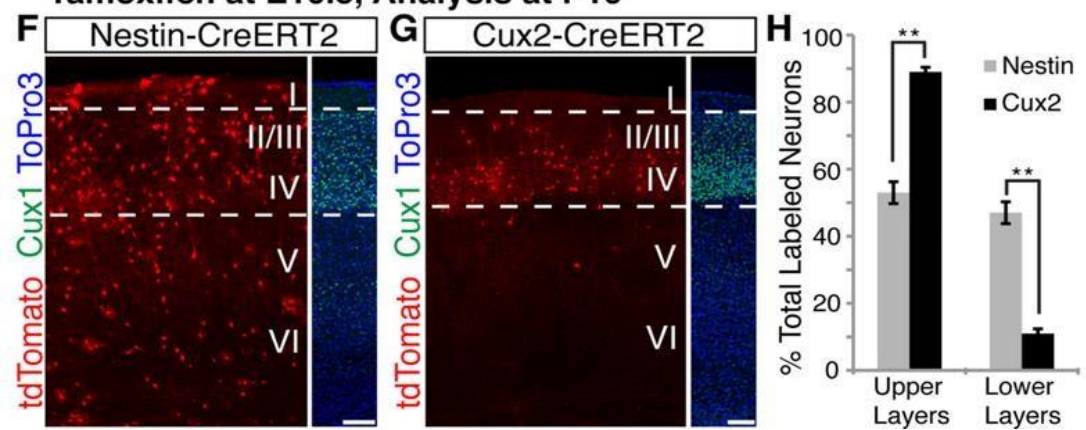

Fig. III. RGCs of the Cux2 lineage are fated to generate upper layer neurons. (A) Temporal fate mapping by in utero electroporation. Upon in utero electroporation into Cux2-Cre embryos, C $\beta$ A-FLEx drives differential expression of tdTomato and eGFP in Cux2- and Cux2 ${ }^{+}$cells, respectively. (B) Electroporation of C $\beta A-F L E x$ at E12.5, analysis at E13.5. Arrows identify cells in the ventricular zone that have recombined the plasmid. (C) Electroporation at E12.5, analysis at P10. (D) Percentage ( \pm SEM) of electroporated $\mathrm{GFP}^{+}$and tdTomato ${ }^{+}$neurons in upper vs. lower layers at P10. ${ }^{*}, P<5 \mathrm{E}-4$. (E) Temporal fate mapping by tamoxifen induction. Cux2- $C r e E R^{T 2}$ mice allow temporary activation of $C r e E R^{T 2}$ in the Cux2 $2^{+}$lineage within 6-24 hr after tamoxifen injection. $C r e E R^{T 2}$ activates the $A i 9$ reporter to allow permanent tdTomato labeling during this window, but not before or after. (F) E10.5 induction, P10 analysis of a Nestin- CreER ${ }^{T 2}$ line, which drives recombination in Cux2 ${ }^{+}$and Cux2- RGCs. Dotted lines frame Cux1 expression in upper layers. (G) E10.5 induction, P10 analysis of the Cux2-CreER ${ }^{T 2}$ line. (H) Percentage $( \pm$ SEM) of recombined neurons in upper vs. lower layers for each driver. ${ }^{*}, P<1 \mathrm{E}-10$. CP, cortical plate. Scale bars, $100 \mu \mathrm{m}$.

From Franco, S.J., Gil-Sanz, C., Martinez-Garay, I., Espinosa, A., Harkins-Perry, S.R., Ramos, C., Müller, U. Faterestricted neural progenitors in the mammalian cerebral cortex. Science. 10 August 2012. 337(6095): $746-749$. Reprinted with permission from AAAS. 
mature cortex, and is necessary for the development of subcerebral projection neurons (Chen et al., 2008; Tantirigama et al., 2014).

Guo et al. first showed with in situ hybridization that Fezf2 is expressed within the VZ of developing embryos. Analysis using a Fezf2-GFP and Fezf2-CreER $R^{T 2}$ transgenic mice, crossed with multiple different reporters, confirmed their localization to the VZ. Indeed, immunostaining for stem cell marker Sox2 (sex determining region Ybox 2) at E11.5 and E16.5 co-labeled with GFP-positive recombined cells at the VZ. This shows that these Fezf2-positive cells are RGCs.

Using the tamoxifen-inducible $F$ ezf2-CreER ${ }^{T 2}$, RGCs were lineage-traced to determine their final laminar position. TM injections at E12.5, E14.5, and E16.5 then examined at postnatal day $21(\mathrm{P} 21)$ revealed a sequential generation of increasingly upper layer-restricted neurons. This result is concordant with the progressive lineage restriction theory (Fig. I). Furthermore, E10.5 Fezf2 RGCs could also generate Cux2-positive neurons at P7 (Fig IV. A-B) However, examining the Fezf2 ${ }^{+}$RGCs revealed that they do not express Cux 2 protein, raising questions regarding the identity of $\mathrm{Cux} 2^{+} \mathrm{RGCs}$ in cortical VZ.

Guo et al. went on to characterize the identity of $\mathrm{Cux} 2^{+} \mathrm{RGCs}$ in order to resolve this discrepancy. Whereas the Franco paper examined Cux2 progeny in the cerebral cortex, previous studies have reported Cux2 expression within interneurons (Zimmer et al. 2004), a neuronal subtype that originates within the medial and caudal ganglionic eminences and migrates into the neocortex (Anderson et al., 1997). To investigate this, they used a Cre reporter system under control of Dlx1/2 (distal-less homeobox 1/2) and 
Nkx2.1 (NK2 homeobox 1), transcription factors expressed in migrating interneurons (Young et al., 2007; $\mathrm{Xu}$ et al., 2004). Indeed, 94\% to $98 \%$ of $\mathrm{Cux}^{+}$cells at E15.5 were found to be migratory interneurons, originating in the ventral $\mathrm{LV}$, and which do not develop into pyramidal neurons that originate in the dorsal LV (Fig. IV. F-J). To reconcile with the results reported by Franco et al. (2012), Guo et al. obtained the Cux2-CreER ${ }^{T 2}$ mice and performed lineage analysis by breeding them to Cre reporter mice. Tamoxifen was administered at E10.5 and brains were analyzed at birth (P0).

Results revealed that a subset of the progeny do end up within the upper layers, as evident by Cux 1 expression (Fig. IV. P-R). However, they also stained for Ctip2 and Tbr1 expression, in roughly equal quantities to Cux1 (Fig. IV. K-O). This shows that TM E10.5 Cux2-CreER ${ }^{T 2}$ progeny can give rise to cells of the superficial Layers 2-4 (Cux1), Layer 5 (Ctip2), and Layer 6 (Tbr1). Altogether, this experiment provides evidence that E10.5 Cux2-positive RGCs produce neurons of all cortical layers and is consistent with the lineage restriction model of cortical development. It contradicts the findings of Franco et al. 2012, which postulated that this RGC subpopulation is lineage restricted to produce only upper layer neurons.

Using the same Cux2-CreER ${ }^{T 2}$ mice, Guo et al. could not reproduce the results presented by Franco et al. 2012. Quantification and analysis showed a significant number of cells expressing deep layer molecular markers (Fig. IV. S). This indicates that the Cux2-positive RGC population were not upper-layer restricted as first suggested.

While Guo et al. presented challenges to the fate-restricted model, there remained a few points of contention. At birth, cortical neurogenesis in mice is completed, but 

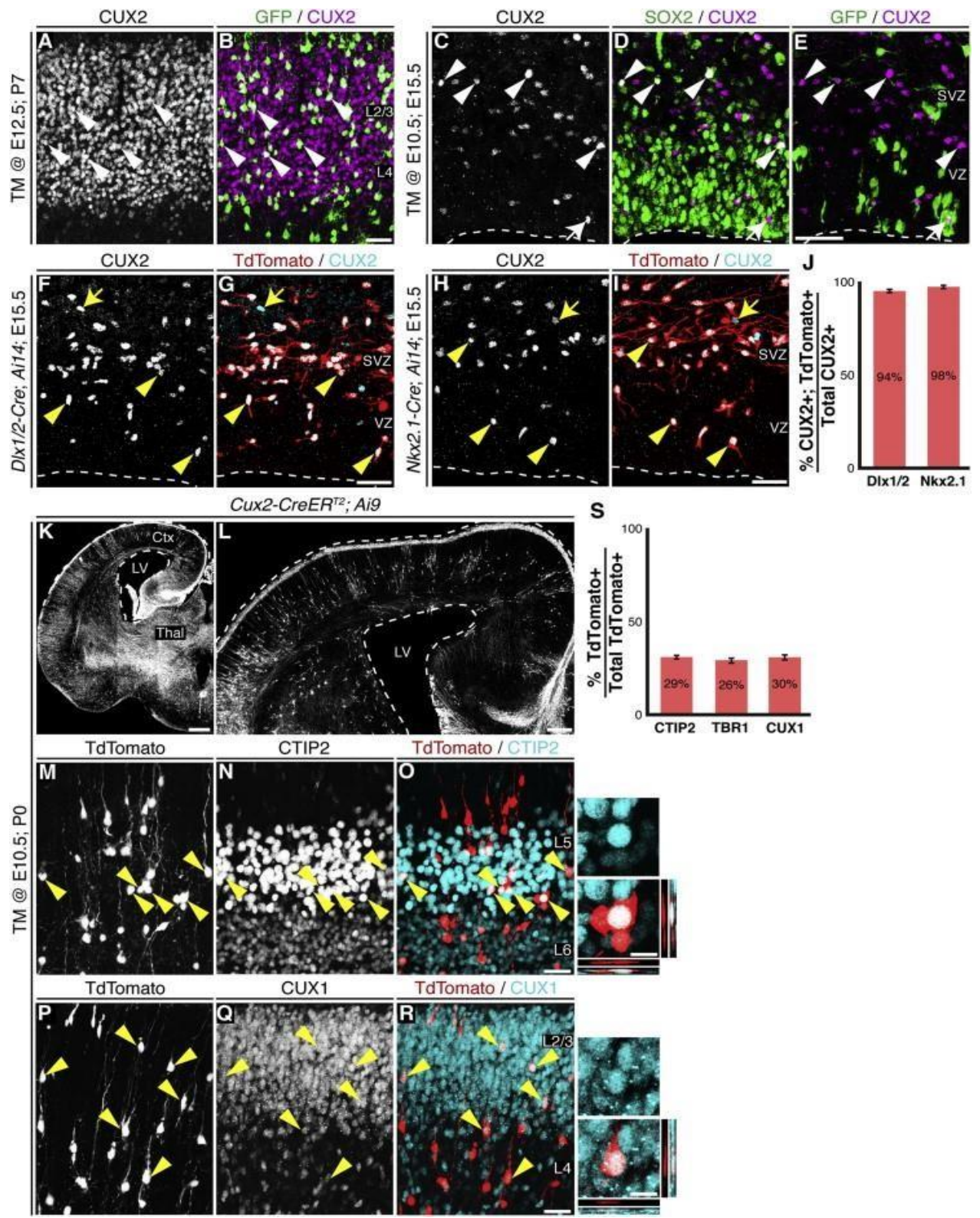

Figure IV. CUX2 ${ }^{+}$Cells in VZ/SVZ Are Migrating Interneurons and Cux2-Cre/CreER ${ }^{T 2}$-Labeled RGCs Generate Both Deepand Upper-Layer Projection Neurons. (A and B) Fezf2 ${ }^{+}$RGCs generated CUX2 ${ }^{+}$upper-layer neurons. (C-E) Immunohistochemical analysis of TM at E10.5; E15.5 Fezf2-CreER ${ }^{T 2}$; RCE-GFP brains. Few CUX2 ${ }^{+}$cells in the SVZ expressed SOX2, and these cells were located at the VZ/SVZ boundary (C and D). Rare CUX2 $2^{+} \mathrm{GFP}^{+}$cell in the VZ/SVZ (E). These CUX2 ${ }^{+} \mathrm{GFP}^{+}$cells did not express SOX2 (D and E). The arrowheads in (C)-(E) point to the CUX2 ${ }^{+} \mathrm{SOX} 2^{+}$cells in VZ/SVZ, and the arrows point to a rare $\mathrm{GFP}^{+} \mathrm{CUX} 2^{+}$ cell. (F-J) Dlx1/2-Cre; Ail4 and Nkx2.1-Cre; Ail4 mice revealed that the majority of CUX2 ${ }^{+}$cells in the E15.5 neocortical VZ/SVZ were interneurons generated from Dlx1/2 (F and G) or Nkx2.1 (H and I) lineages. Quantification of the percentage of $\mathrm{CUX2}^{+} \mathrm{TdT}$ Tato $^{+}$cells among all CUX2 ${ }^{+}$cells in the VZ/SVZ $\pm \mathrm{SEM}(\mathrm{J})$. (K and L) TM at E10.5; P0 Cux2-CreER ${ }^{T 2}$; Ai9 brains contained TdTomato ${ }^{+}$cells in all cortical layers. $(\mathrm{M}-\mathrm{O})$ TdTomato $^{+}$cells in deep layers expressed CTIP2. (P-R) Upper-layer TdTomato $^{+}$cells expressed CUX1. (S) Percentage of TdTomato ${ }^{+}$cells in layers 2-6 that expressed CTIP2, TBR1, or CUX1 \pm SEM. Ctx, cerebral cortex; LV, lateral ventricle; SVZ, subventricular zone; Thal, thalamus; TM, tamoxifen; VZ, ventricular zone. Scale bars: $25 \mu \mathrm{m}$ (B, E, G, I, O, and R), $500 \mu \mathrm{m}(\mathrm{K}), 200 \mu \mathrm{m}(\mathrm{L})$, and $10 \mu \mathrm{m}$ (close-ups from O and R)

Reprinted with permission from Guo, C., Eckler, M.J., McKenna, W.L., McKinsey, G.L., Rubenstein, J.L.R., Chen, B. Fezf2 Expression Identifies a Multipotent Progenitor for Neocortical Projection Neurons, Astrocytes, and Oligodendrocytes. Neuron. 4 Dec. 2013. 
later-born upper-layer neurons are still migrating. Therefore, examination of $\mathrm{Cux2-}$ $C r e E R^{T 2}$ mice should be carried out through a later time point when neuronal migration is finished. Furthermore, although early Fezf2 $2^{+}$and $\mathrm{Cux} 2^{+} \mathrm{RGC}$ populations are multipotent, it is possible there exist a population of intrinsically lineage-restricted early RGCs that are not specifically labeled by the expression of either Fezf2 or Cux2.

These issues led to my thesis project. To determine whether there are early lineage-restricted RGCs or not, I performed clonal analysis of individual E10.5 Cux2+ and Fezf2 ${ }^{+}$RGCs. I examined the cerebral cortex at postnatal day 21 (P21), a point well past the termination of cortical development. Furthermore, I investigated progeny laminar distribution as well as molecular identity. This establishes which layers these cells reside in, as well as an idea of their function (L6 corticothalamic, L5 corticospinal, or L2-4 callosal projection neurons) with a high degree of confidence. I also investigated the axonal projection of the lineage-traced neurons by combining lineage analysis with retrograde axonal tracing.

Our results ultimately show no disparity between either the Cux 2 or Fezf 2 lineages in terms of lineage potential. The lineages of individual Cux2-positive RGCs appear consistent with the progressive lineage restriction theory. We found no evidence that they are layer restricted at even the clonal level. 


\section{CHAPTER II}

The following is printed as is from an accepted manuscript and is titled

\section{CUX2-POSITIVE RADIAL GLIAL CELLS GENERATE DIVERSE SUBTYPES OF NEOCORTICAL PROJECTION NEURONS AND MACROGLIA}

and was published concurrently with the rebuttal from Gil-Sanz et al.

\section{LINEAGE TRACING USING CUX2-CRE AND CUX2-CREER ${ }^{T 2}$ MICE}

on May 20, 2015 in Matters Arising of the journal Neuron, a division of Cell Press. 


\section{Cux2-Positive Radial Glial Cells Generate Diverse Subtypes of Neocortical Projection Neurons and Macroglia}

Matthew J. Eckler ${ }^{1,4,5}$, Ton D. Nguyen ${ }^{1,2,5}$, William L. McKenna ${ }^{1}$, Chao Guo ${ }^{1}$, John L. R. Rubenstein ${ }^{3}$, and Bin Chen ${ }^{1, *}$

1

Department of Molecular, Cell and Developmental Biology, University of California, Santa Cruz, CA 95064, USA

2

Department of Biological Sciences, San Jose State University, San Jose, CA 95192, USA

3

Department of Psychiatry and Nina Ireland Laboratory of Developmental Neurobiology, University of California, San Francisco, CA 95158, USA

4

Current address: Section of Neurobiology, Division of Biological Sciences, University of California, San Diego, CA 92093, USA

5

These authors contributed equally to this work

*Correspondence: bchen@ucsc.edu 


\begin{abstract}
The progressive lineage restriction model indicates that radial glia cells (RGCs) are gradually constrained to produce neurons in increasingly superficial layers of neocortex through cortical development. This restriction is temporally regulated by progeny birthdate. Recent studies have suggested the existence of a subpopulation of RGCs expressing Cux2 that appear intrinsically fated at an early embryonic date (E10.5) to generate exclusively upper layer (L2/3 - 4) callosal projection neurons. These studies were predicated on genetic lineage tracing experiments incorporating Cux2-Cre and Cux2-CreER ${ }^{T 2}$ mediated recombination. Recently, we published a study examining $\mathrm{Fezf}^{+}$and $\mathrm{Cux} 2^{+} \mathrm{RGC}$ lineage potential. Our experiments demonstrated that early embryonic Fezf $2^{+}$and $\mathrm{Cux} 2^{+}$RGCs are multipotent, have progenies spanning all cortical layers, and generate a diverse array of projection neuronal subtypes as well as macroglia. Here, we extend our previous work and provide further support to our initial conclusion that both Fezf $2^{+}$and $\mathrm{Cux} 2^{+}$RGCs are multipotent neocortical progenitors.
\end{abstract}




\section{Introduction}

Recent work proposes that the neocortex contains distinct classes of radial glial cells (RGCs), which are intrinsically predisposed to generate either deep or upper layer projection neurons. This model is based upon genetic lineage-tracing experiments, which concluded that early (embryonic day 10.5 [E10.5]) RGCs labeled by Cux2-Cre or Cux $2 \mathrm{CreER}^{T 2}$-mediated recombination $\left(\mathrm{Cux}^{+}\right)$are fated to generate corticocortical projection neurons that reside primarily within upper layers (Franco et al., 2012).

We recently published a study in which we tested this model using genetic lineage tracing with the Fezf2 and Cux2 loci. This work demonstrated that: (1) Fezf2-expressing $\left(\right.$ Fezf $\left.^{+}\right)$RGCs are multipotent and sequentially generate deep and upper layer cortical projection neurons followed by macroglia and (2) RGCs marked by Cux2-

CreER $R^{T 2}$ mediated recombination are not fate restricted to generate only corticocortical projection neurons. Collectively, these results do not support the existence of early laminar-restricted RGCs within either the Fezf $2^{+}$or $\mathrm{Cux} 2^{+} \mathrm{RGC}$ lineages. Thus, although our results did not exclude their existence, they demonstrated that neither Fezf2 nor Cux2 expression alone is sufficient to identify fate-restricted RGCs.

Here, in response to challenges raised by Gil-Sanz et al. (2015), we extend our work on the lineages of Fezf $2^{+}$and $\mathrm{Cux} 2^{+}$RGCs. We show that the Cux2-Cre allele does not accurately report the lineage of neocortical RGCs. Moreover, clonal analysis of E10.5 RGCs using Cux2-CreER $R^{T 2}$ and Fezf2-CreER $R^{T 2}$ mice indicates that most, if not all, early RGCs labeled by these alleles generate multiple subtypes of cortical projection neurons 
located in layers 2-6. These results reinforce our previous conclusion that both Fezf2+ and $\mathrm{Cux}_{2}{ }^{+}$RGCs are multipotent neocortical progenitors (Guo et al., 2013).

\section{Results}

\section{The Cux2-Cre Allele Is Not Suitable for Lineage Tracing of Neocortical RGCs}

A significant difference between our previous study (Guo et al., 2013) and the work of Franco et al. (2012) and Gil-Sanz et al. (2015) is that the latter two studies relied extensively on the $\mathrm{Cux2-Cre}$ allele to analyze the lineages of RGCs. This allele expresses a constitutively active form of Cre that, when utilized in combination with Cre-dependent reporters, permanently labels any cell in which the $C u \times 2$ locus has been, or is currently, active. In addition, any cell derived from a $\mathrm{Cux}_{2}^{+}$progenitor will be permanently labeled.

We reported that at E15.5, Cux2-Cre labeled RGCs, basal progenitors, and postmitotic neurons, thus masking the true lineage of $\mathrm{Cux} 2^{+}$RGCs (Guo et al., 2013). To demonstrate this further, we bred heterozygous $\mathrm{Cux2}$-Cre mice to homozygous RCE-GFP and Ai9 reporter mice and examined the brains of double heterozygous mice at postnatal day 28 (P28) (Figures S1A and S1B and data not shown). We observed strong fluorescence throughout all cortical layers. Although in some cases labeling of cell bodies was evident (Figure S1B), high levels of reporter expression in neurites complicated the analysis of labeled cell bodies.

To circumvent this, we examined publicly available data from the Allen Brain Atlas (ABA), which includes extensive analysis of the same Cux2-Cre and $\mathrm{Cu} x 2 \mathrm{CreER}{ }^{T 2}$ alleles that were used in previous lineage studies (Franco et al., 2012 and Guo et al., 2013). The ABA datasets include in situ hybridization (ISH) experiments for Cre, 
Cux2, and tdTomato, which facilitate high-resolution analysis of cell bodies labeled by the Cre-dependent tdTomato reporter Ai14 (Madisen et al., 2010). Analysis of P58 Cux2Cre; Ai14 mice indicated that Cre expression closely mimicked Cux 2 expression (Figures S1C-S1F). Both Cux2 and Cre transcripts were highly enriched within upper cortical layers (L2-L4) with sparse expression in deep layers (L5 and L6). P56 Cux2-CreER ${ }^{T 2}$; Ai14 mice, which received daily administration of tamoxifen (TM) from P45 to P49, had many tdTomato ${ }^{+}$cells in L2-L4, with sparse cell labeling in deep layers (Figures S1G and $\mathrm{S} 1 \mathrm{H})$. This expression of tdTomato mRNA indicates that Cre recombinase driven by the Cux2 locus is active in postmitotic neurons.

Compared to Cux2 and Cre expression however, tdTomato (Figures S1I and S1J) was more broadly expressed throughout both deep and upper cortical layers in P56 Cux2Cre; Ai14 mice (compare Figures S1C-S1F with Figures S1I and S1J). Indeed, while double fluorescence in situ hybridization (dFISH) for Cux2 and tdTomato demonstrated significant co-expression in upper layer cells, many tdTomato ${ }^{+}$cells in L5 and L6 did not express Cux2 (Figures S1K-S1O). This suggests that these deep layer tdTomato ${ }^{+}$cells originated from $\mathrm{Cux} 2^{+}$progenitors or immature neurons but subsequently reduced their Cux 2 expression in adult stages.

To further evaluate the distribution of tdTomato ${ }^{+}$cells in P56 Cux2-Cre; Ai14 brains, we analyzed ABA experiments No. 100144051 (which is the same experiment shown in Figure S1 of Gil-Sanz et al. [2015]) and No. 113098686. Mice analyzed in these experiments were generated by breeding $\mathrm{Cux2}$-Cre heterozygous mice with Ai14 homozygous reporter mice. We examined multiple cortical areas including the 
somatosensory, somatomotor, primary motor, and visual cortices, as well as the anterior cingulate and posterior parietal areas. We found that tdTomato was robustly expressed throughout both deep and upper cortical layers (Figures S1I, S1J, and S2). However, in some cortical areas, particularly the anterior cingulate area, there were fewer tdTomato ${ }^{+}$ cells in deep layers (compare Figures S2D2 and S2H2 with S2B-S2D1 and S2F-S2H1). This indicates that a thorough examination of reporter expression across multiple cortical areas is required to fully understand the extent of cell labeling by the Cux2-Cre allele, as it has a complex temporal and spatial expression pattern (Figure 1A).

The preceding analysis demonstrates that, in the adult brain, the Cux2-Cre allele labels cells that are present in both deep and upper cortical layers, including cells that no longer express $\mathrm{Cux} 2$ at adult stages. Importantly, the recombinase activity of $\mathrm{Cux} 2$-Cre in both progenitor cells and postmitotic neurons makes it unsuitable for lineage analysis of neocortical RGCs, because the possibility cannot be excluded that Cux2-Cre-mediated recombination was initiated in postmitotic neurons (Figure 1A). A projection neuron labeled by Cux2-Cre may have originated from a $\mathrm{Cu} 2 \mathrm{x} 2 \mathrm{Cr} \mathrm{e}^{+} \mathrm{RGC}$, a $\mathrm{Cu} \mathrm{x} 2-\mathrm{Cr} \mathrm{e}^{+}$basal progenitor, or it may have turned on Cre expression postmitotically. Accordingly, the expression of reporter alleles in Cux2-Cre mice is not reflective of the developmental origin of the cells that express the reporter (Figure 1A).

E10.5 RGCs Marked by Cux2-CreER ${ }^{T 2}$ Generate Neocortical Projection Neurons in Both Deep and Upper Layers and Macroglia

Our previous work demonstrated that at the population level, $\mathrm{Cux} 2^{+} \mathrm{RGCs}$ are not fate restricted to generate only corticocortical projection neurons (Guo et al., 2013). To 
Figure 1
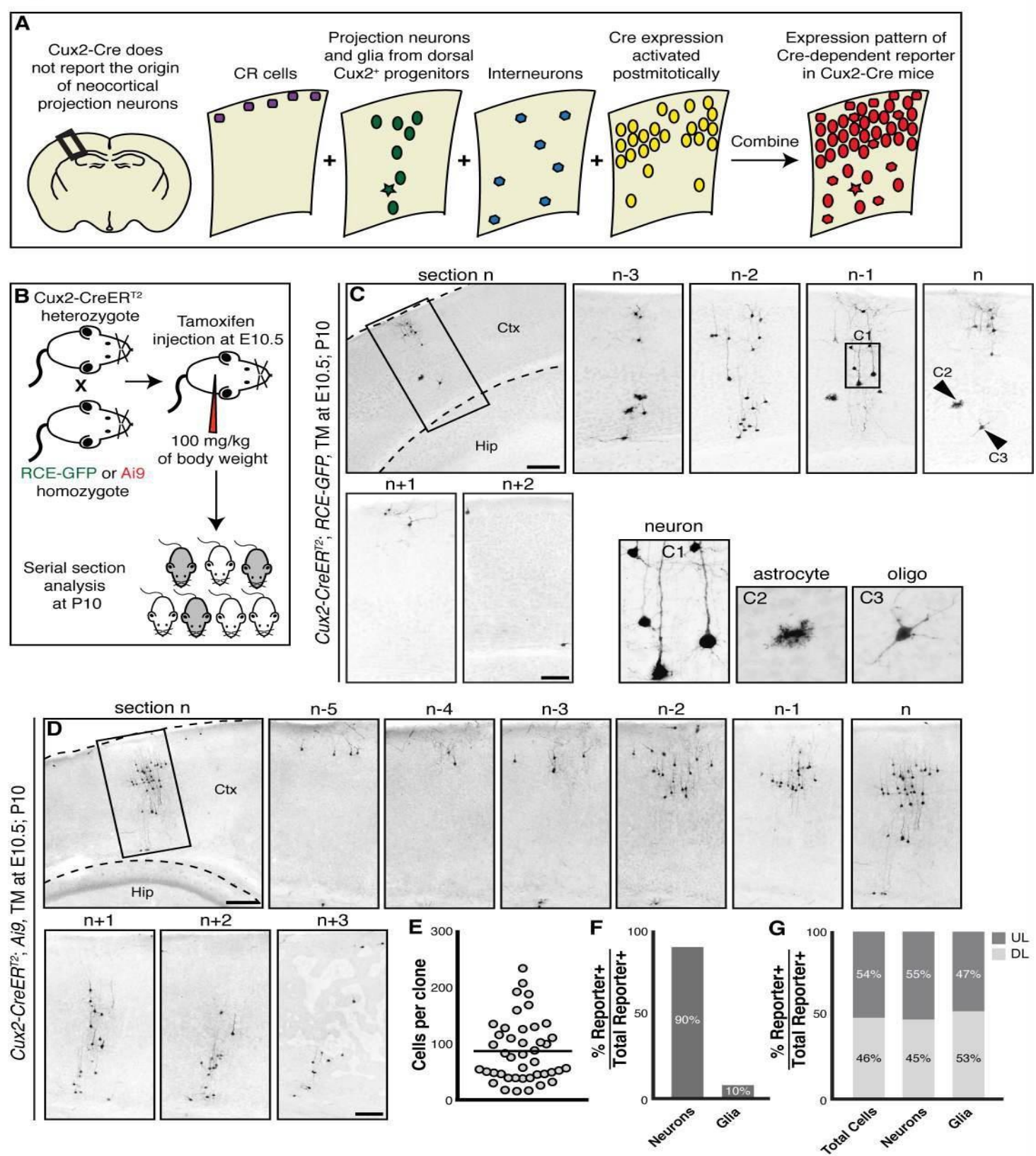

Figure 1. Individual E10.5 Cux2+ RGCs generate cortical projection neurons and macroglia located throughout cortical layers 2-6. (A) The complex temporal and spatial expression pattern of the Cux2-Cre allele makes it unsuitable for lineage analysis of neocortical RGCs. (B) Experimental methodology. (C-D) Examples of TM at E10.5, P10 Cux2 ${ }^{+}$RGC clones. For each clone, a lower magnification image is shown first to illustrate the position of the clone in the cerebral cortex, followed by higher magnification images of serial sections that span the entire clone. Panels (C1), (C2) and (C3) show neurons, an astrocyte, and an oligodendrocyte found within the clone shown in (C). (E) Scatter plot of the number of cells for each of the 43 clones analyzed. (F) Quantification of the percentages of neurons and glia generated from E10.5 Cux2 $2^{+}$GCs based upon the analysis of 43 fully reconstructed clones. (G) Quantification of the percentages of all lineage traced cells, neurons, and glia that were located in deep or upper layers. Abbreviations: CR, Cajal-Retzius cells; Ctx, cerebral cortex; DL, deep cortical layers (layers 5 and 6); Hip, hippocampus; UL, upper cortical layers (layers 2-4). Scale bars: (C, D) $500 \mu \mathrm{m}$, (Inserts) $250 \mu \mathrm{m}$. 
extend our analysis, we performed lineage-tracing experiments using the $C u x 2-C r e E R^{T 2}$ allele, which expresses an inducible form of Cre that only induces recombination of a reporter allele for approximately $24-48 \mathrm{hr}$ following tamoxifen administration. This enables labeling of $\mathrm{Cux} 2^{+} \mathrm{RGCs}$ during a short temporal window in order to track their progeny. In these experiments, we crossed heterozygous $C u \times 2-C r e E R^{T 2}$ mice to homozygous RCE-GFP (Sousa et al., 2009) or Ai9 (Madisen et al., 2010) reporter mice. A single dose of tamoxifen was injected at E10.5, a time at which postmitotic neurons and intermediate progenitors are largely absent in the developing cortex. Brains from Cux2-CreER ${ }^{T 2} ; A i 9$ and $C u x 2-C r e E R^{T 2} ; R C E-G F P$ mice were collected at P10 (TM at E10.5; P10), after cortical projection neurons have migrated to their final laminar position (Chen et al., 2008 and Miyoshi and Fishell, 2012) (Figure 1B). We injected tamoxifen at $100 \mathrm{mg}$ per $\mathrm{kg}$ of body weight, a concentration that reliably generated sparse labeling in the cortices of these mice. Whole-mount examination of the brains revealed sparse columns of reporter ${ }^{+}$cells (Figure S3A), suggesting that these cells may be clonally related. Although we refer to the spatially isolated columns of labeled cells as clones, we cannot exclude the possibility that some of the clones may consist of progeny from more than one RGC. This caveat, however, does not change the interpretation of our analysis with regard to the lack of lineage restriction within the $\mathrm{Cux} 2^{+} \mathrm{RGC}$ lineage.

To examine the progeny of early $\mathrm{Cux} 2^{+} \mathrm{RGCs}$, we analyzed serial brain sections and reconstructed 43 clones from 6 mice (Figures 1C-1D and S3C and Table S1). We focused our analysis on spatially isolated columns of cells that predominantly consisted of projection neurons and macroglia. We excluded individual cells that were sparsely 
distributed throughout the cortex, as they were likely labeled interneurons. The number of cells in each clone varied from 13 to 227 with an average of 83 cells per clone (Figure 1E and Table S1). Cells in the clones spanned an average of $350 \mu \mathrm{m}$ along the rostral-caudal axis (Table S1). The number of cells per clone and physical dispersion of the cells in the clones is similar to that reported for E10.5 RGC clones in a recent study that utilized Mosaic Analysis with Double Markers (MADM) to label RGC progeny at clonal density (Gao et al., 2014). Of the 43 reconstructed clones, 30 (70\%) contained both neurons and glia, while 13 (30\%) consisted of only neurons (Table S1). Strikingly, 100\% of the E10.5 Cux2-CreER ${ }^{T 2}$-labeled clones that we examined contained projection neurons located in cortical layers 2-6 (Figures 1C-1D and S3C). The 43 reconstituted clones contained a total of 3,562 lineage-traced cells of which 90\% exhibited a characteristic neuronal morphology while 10\% exhibited glial morphologies (Figure 1F and Table S1). Analysis of the 3,188 lineage-traced neurons demonstrated that their distribution in deep and upper layers was roughly equivalent (55\% upper layer neurons versus $45 \%$ deep layer neurons) (Figure 1G and Table S1). This distribution of lineage-traced neurons is similar to that observed in lineage-tracing experiments of E10.5 RGCs using the Nestin-CreER ${ }^{T 2}$ (Franco et al., 2012), Emxl-CreER ${ }^{T 2}$ (Gao et. al. 2014), and Fezf2-CreER $R^{T 2}$ alleles (Figure 3 and Table S1). These results provide strong evidence that most, if not all, individual $\mathrm{Cux}^{+} \mathrm{RGCs}$ are multipotent and generate projection neurons in cortical layers 2-6 and macroglia. 


\section{Molecular analysis of the Cux2 lineage}

We next analyzed the molecular expression profiles of tdTomato ${ }^{+}$and $\mathrm{GFP}^{+}$cells in TM at E10.5; $\mathrm{P} 10, \mathrm{Cu} \times 2-\mathrm{CreER}^{T 2} ; A i 9$ and $C u \times 2-\mathrm{CreER}^{T 2} ; R C E-G F P$ mice. To restrict our analysis to the progeny of neocortical $\mathrm{Cux} 2^{+} \mathrm{RGCs}$, we focused only on projection neurons and glia that were part of putative RGC clones and excluded the sparsely distributed individual cells that were likely interneurons. We analyzed 6,258 neocortical cells from 4 animals. Among 2,583 lineage-traced deep layer neurons, $33.9 \% \pm 9.5 \%$ expressed the subcerebral neuron marker CTIP2 (McKenna et al., 2011 and Molyneaux et al., 2005) (Figures 2A-2T and 2AA). When lineage-traced, deep layer neurons were analyzed by double labeling with antibodies for CTIP2 and TBR1, a marker for corticothalamic neurons (Bedogni et al., 2010, Han et al., 2011, Hevner et al., 2001 and McKenna et al., 2011), $23.7 \% \pm 8.7 \%$ expressed TBR1 alone, and $18.8 \% \pm 3.8 \%$ expressed both TBR1 and CTIP2 (Figures 2A-2E and 2AA). Similar results were observed with another corticothalamic neuron marker DARPP32 (McKenna et al., 2011), which was co-expressed in $\mathrm{TdTomato}^{+}$or $\mathrm{GFP}^{+}$deep layer neurons (Figures $2 \mathrm{~F}-2 \mathrm{~J}$ ). We also investigated molecular expression profiles using a combination of antibodies against CTIP2 and SATB2, another projection neuron marker (Alcamo et al., 2008 and Britanova et al., 2008). Within L5 and L6, 35.8\% $\pm 5.7 \%$ of lineage-traced neurons expressed SATB2 and $13.2 \% \pm 2.5 \%$ expressed both SATB2 and CTIP2 (Figures $2 \mathrm{~K}-2 \mathrm{O}$ and 2AA). Thus, within deep cortical layers, projection neurons generated from E10.5 Cux2 ${ }^{+}$ RGCs express four molecular markers previously associated with different projection neuron subtypes. 
Figure 2

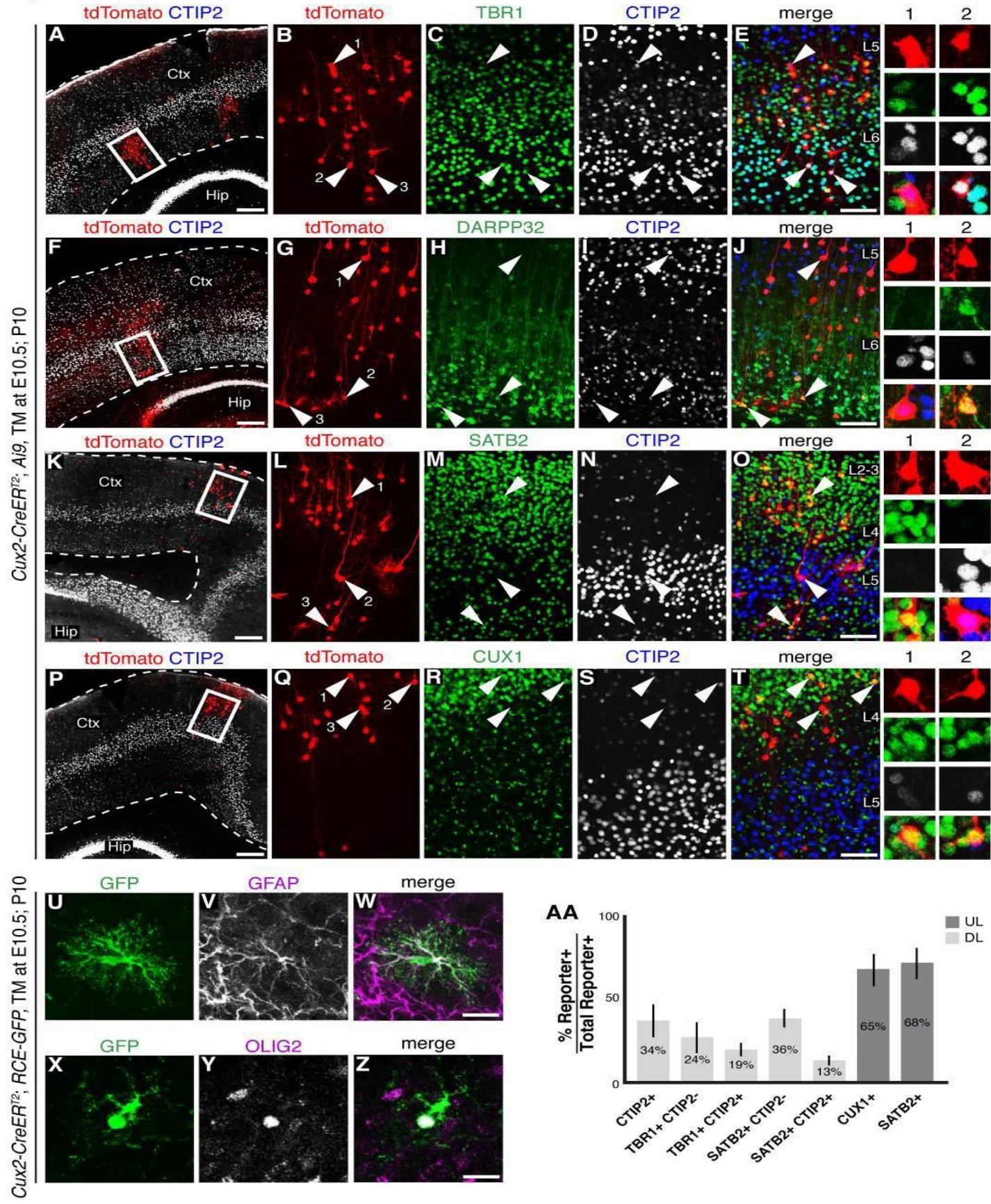

Figure 2. Cux $2^{+}$RGCs generate diverse, molecularly defined subtypes of cortical projection neurons and macroglia. All images are of brain sections from P10 Cux2-CreER ${ }^{T 2}$; Ai9 (A-T) or P10 Cux2-CreER $R^{T 2}$; RCE-GFP (U-Z) mice that received a single tamoxifen injection at E10.5 (TM at E10.5; P10). Lineage traced neurons expressed TBR1 (A-E), DARPP32 (F-J), SATB2 (K-O), CUX1 (P-T), or CTIP2 (A-T). Panels (B-E), (G-J), (L-O), and (Q-T) show the higher magnification images of the boxed areas in panels (A), (F), (K) and $(\mathrm{P})$ respectively. The arrowheads in (B-E), (G-J), (L-O) and (Q-T) point to cells that are shown in higher magnification to the right. (U-Z) E10.5 lineage-traced Cux2 ${ }^{+}$RGCs generated astrocytes that expressed GFAP (U-W) and oligodendrocytes that expressed OLIG2 (X-Z). (AA) Percentages of lineage-traced deep-layer and upper-layer neurons that expressed the indicated markers. Error bars

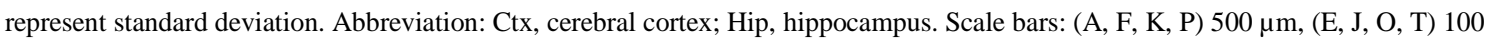
$\mu \mathrm{m},(\mathrm{W}, \mathrm{Z}) 25 \mu \mathrm{m}$. 
We examined 3,064 tdTomato ${ }^{+}$or $\mathrm{GFP}^{+}$neurons within the upper layers (L2-L4) of TM at E10.5; P10 Cux2-CreER ${ }^{T 2}$; Ai9 or $\mathrm{Cux2-CreER^{T2 }}$; RCE-GFP mice. As expected, significant numbers of these cells expressed CUX1 (64.6\% $\pm 8.2 \%)$ (Cubelos et al., 2010) or SATB2 (68.3\% \pm 10.4\%) (Alcamo et al., 2008 and Britanova et al., 2008), two markers previously associated with upper layer callosal projection neurons (Figures $2 \mathrm{~K}-2 \mathrm{~T}$ and $2 \mathrm{AA})$. In addition, some lineage-traced cells exhibited characteristic astrocyte or oligodendrocyte morphology and expressed GFAP or OLIG2, respectively (Figures 2U-2Z). Thus, results from molecular expression analyses further strengthen the evidence that early $\mathrm{Cux} 2^{+} \mathrm{RGCs}$ are not lineage restricted to generate only upper layer or corticocortical projection neurons. Rather, these data support the conclusion that $\mathrm{Cux}^{+}$ RGCs generate a diversity of projection neuron subtypes and macroglia that reside within both deep and upper cortical layers.

\section{$\mathrm{Cux2}^{+}$RGCs and $\mathrm{Fezf}^{+}{ }^{+}$RGCs generate similar progeny}

We previously demonstrated that early Fezf2 ${ }^{+}$RGCs are multipotent and sequentially generate projection neurons and macroglia (Guo et al., 2013). To extend our clonal analysis of Fezf2 ${ }^{+}$RGCs, we bred Fezf2-CreER $R^{T 2}$ animals to RCE-GFP or Ai9 reporter mice, administered a single low dose of tamoxifen at E10.5, and analyzed brains at P10 (Figure 3A). We reconstituted 46 clones from 3 animals (Figures 3B-3C and S3D and Table S1). The number of cells in each clone varied from 13 to 242 with an average of 67 cells per clone, and the clones spanned an average of $300 \mu \mathrm{m}$ along the rostralcaudal axis (Figure 3D and Table S1). Twenty-eight percent of the clones contained only neurons, and $72 \%$ contained both neurons and glia. Similar to E10.5 Cux2 ${ }^{+}$RGCs, $100 \%$ 
Figure 3
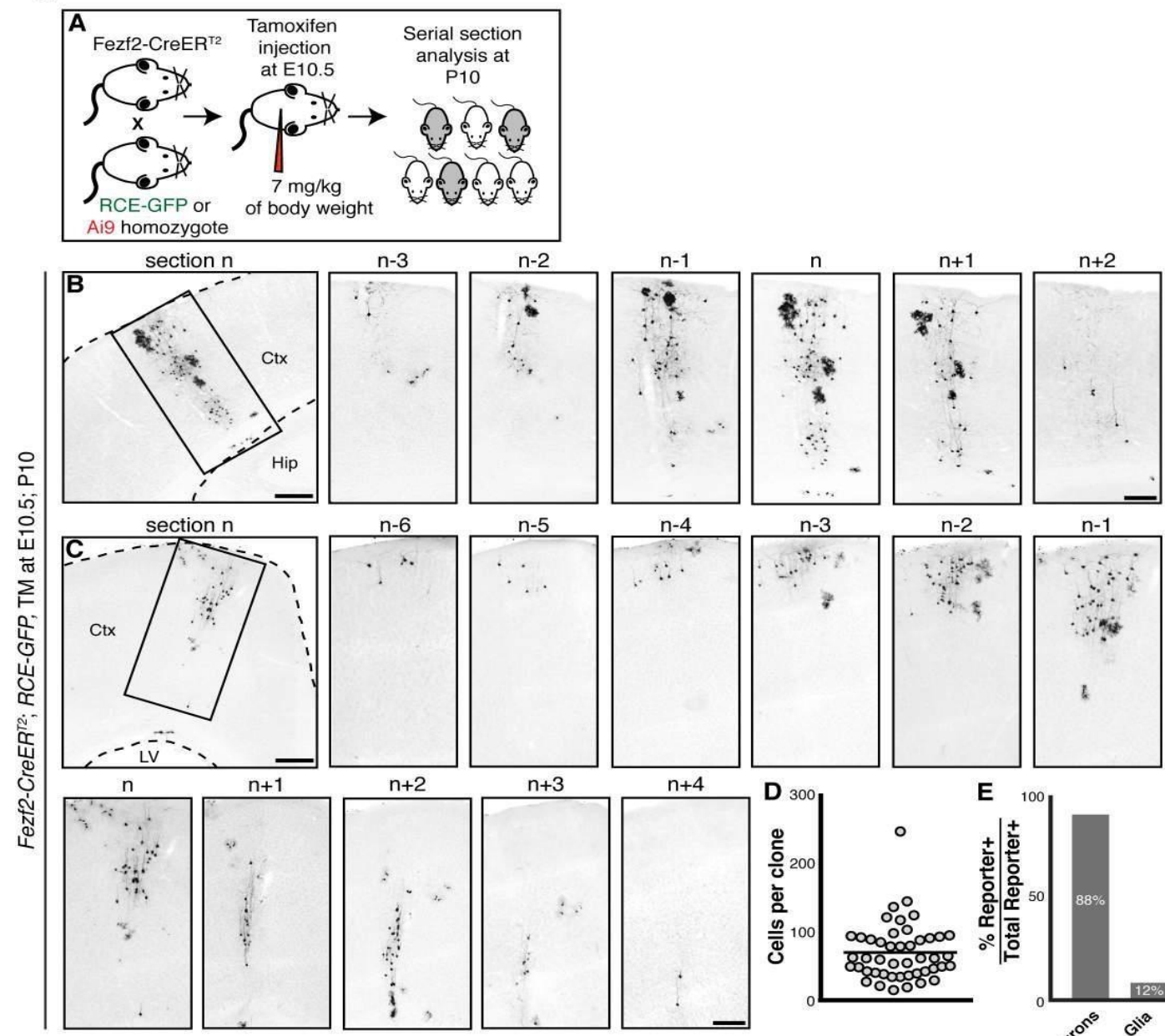

$\mathrm{n}-3$
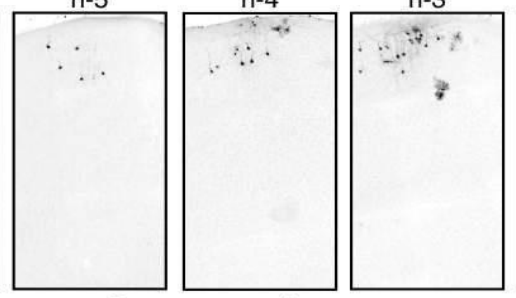

$\mathrm{n}-2$
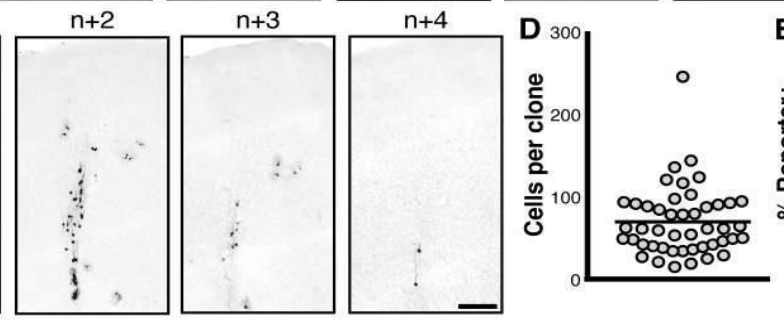

E

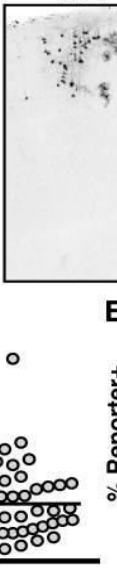

$\mathrm{n}-1$
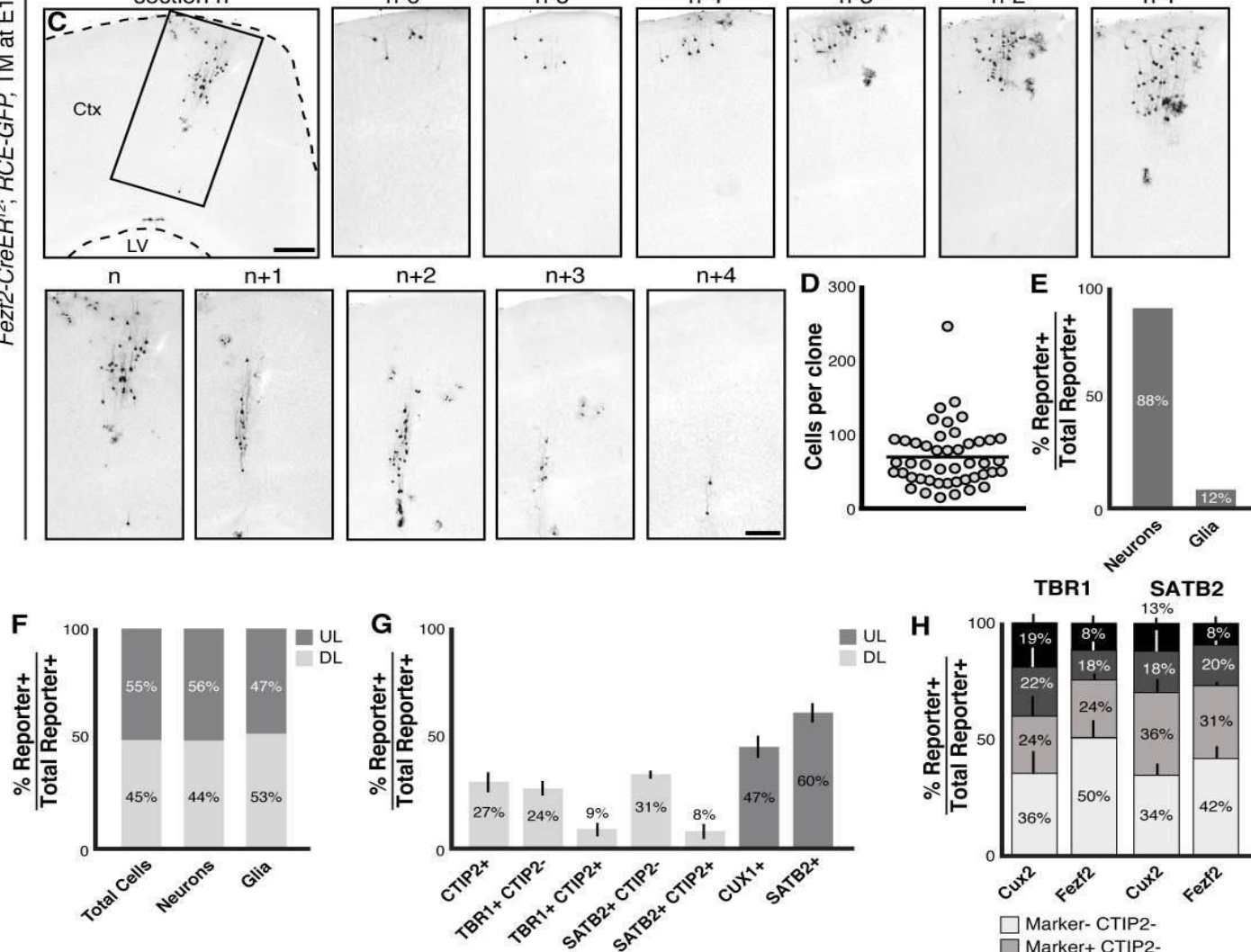

SATB2

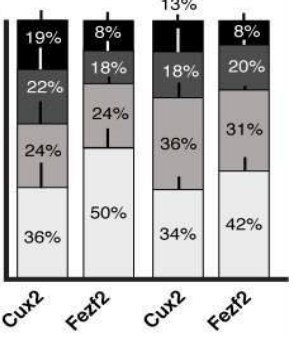

$\square$ Marker- CTIP2-

Marker+ CTIP

Marker- CTIP2+

Marker+ CTIP2+

Figure 3. Similar to early Cux2 $2^{+}$RGCs, E10.5 Fezf2 ${ }^{+}$RGCs generate diverse subtypes of cortical projection neurons and glia. (A) Experimental methodology. (B-C) Two examples of clones generated from E10.5 Fezf2 ${ }^{+}$RGCs. For each clone, a lower magnification image is shown first to illustrate the position of the clone in the cerebral cortex, followed by higher magnification images of serial sections that span the full clone. (D) Scatter plot of the number of cells for each of the 46 clones analyzed. (E) Quantification of the percentages of lineage-traced cells that were neurons or glia. (F) Quantification of the percentages of lineage-traced cells, neurons, and glia that were located in deep and upper cortical layers. (G) Percentages of lineage-traced deep-layer and upper-layer neurons that expressed the indicated markers. $(\mathrm{H})$ Percentages of deep-layer neurons generated from E10.5 Cux2 ${ }^{+}$or E10.5 Fezf $2^{+}$RGCs that expressed combinations of either CTIP2/TBR1 or CTIP2/SATB2. Error bars represent standard deviation. Abbreviation: Ctx, cerebral cortex; Hip, hippocampus; LV, lateral ventricle. Scale bars: (A, B, C) $500 \mu \mathrm{m}$, (Inserts) $250 \mu \mathrm{m}$. 
of Fezf2 ${ }^{+}$RGC clones contained neurons located throughout cortical of the 3,100 lineagetraced cells in the 46 E10.5 Fezf2 clones and found that, comparable layers 2-6 (Figures 3B-3C and S3D). We quantified the distribution to results from clonal analysis using the Cux2-CreER ${ }^{T 2}$ allele, Fezf2 ${ }^{+}$RGCs generated projection neurons (88\%) and glia (12\%) (Figure 3E and Table S1). Lineage-traced neurons were located in both deep (44\%) and upper (56\%) layers (Figures 3B-3C and 3F and Table S1).

We examined 2,328 deep layer lineage-traced neurons from 3 brains that consisted of both fully and partially reconstructed clones and found that $26.8 \% \pm 5.0 \%$ of these neurons expressed CTIP2 (Figure 3G). When lineage-traced neurons were analyzed using antibodies for CTIP2 and TBR1, 23.5\% $\pm 3.0 \%$ of deep layer neurons expressed TBR1 alone, and $8.8 \% \pm 2.9 \%$ expressed both CTIP2 and TBR1 (Figure 3G). We also analyzed reporter ${ }^{+}$neurons in L5 and L6 using a combination of CTIP2 and SATB2 antibodies and found that $30.8 \% \pm 1.4 \%$ expressed SATB2 alone, and $7.6 \% \pm 3.3 \%$ expressed both SATB2 and CTIP2 (Figure 3G). Within upper cortical layers, lineagetraced neurons expressed CUX1 $(47.1 \% \pm 5.9 \%)$ or SATB2 $(59.7 \% \pm 4.7 \%)$ (Figure 3G). Notably, the percentage of lineage-traced neurons that expressed each of these markers is similar to that observed with TM at E10.5; P10 Cux2-CreER ${ }^{T 2}$ mice (Figures 2AA, 3G, and $3 \mathrm{H})$. Collectively, our clonal and molecular analyses suggest that both Fezf2 ${ }^{+}$RGCs and $\mathrm{Cux}_{2}{ }^{+}$RGCs are multipotent and generate multiple subtypes of projection neurons and macroglia. 


\section{Retrograde tracing confirms that $\mathrm{Cux2}{ }^{+}$RGCs generate subcerebral projection}

\section{neurons}

Thus far, we have provided evidence that $\mathrm{Cux} 2^{+} \mathrm{RGCs}$ generate neurons located in deep cortical layers that also express molecular markers for subcerebral projection neurons. To confirm that these neurons extend axons to subcerebral targets, we combined Cre-dependent lineage analysis with retrograde tracing (Figure 4A). We bred heterozygous $\mathrm{Cux2}-\mathrm{CreER} \mathrm{R}^{T 2}$ mice to homozygous RCE-GFP reporter mice, and administered a single dose of tamoxifen at E10.5 (100 mg/kg), to mark the progeny of $\mathrm{Cux}^{+}$RGCs. We then injected cholera toxin beta $(\mathrm{Ct} \beta)$ into the pyramidal tract at P8 (Figures 4A and S3B).

$\mathrm{Ct} ß$ injection into the pyramidal tract labeled a subset of subcerebral projection neurons located in layer 5 (Figure 4C). Notably, we observed GFP; Ctß double-positive

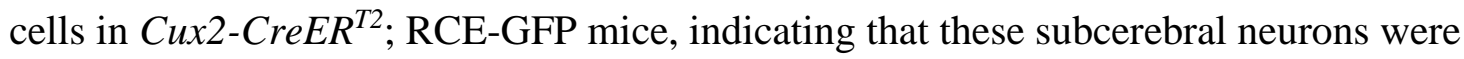
generated from Cux2 $2^{+}$RGCs (Figures 4D-4F). We quantified the percentage of $\mathrm{GFP}^{+}$ cells derived from Cux2 ${ }^{+}$RGCs that projected subcerebral axons in $\mathrm{Cu} 2-\mathrm{CreER}^{T 2}$; RCEGFP brains. We found that $11.5 \% \pm 1.1 \%$ of $\mathrm{GFP}^{+}$cells in layer 5 and $4.4 \% \pm 0.4 \%$ of $\mathrm{GFP}^{+}$cells in layers 5 and 6 were retrogradely traced (Figure 4B).

We performed a similar analysis using the Fezf2-CreER ${ }^{T 2}$ allele (Figures 4A and $4 \mathrm{G}-4 \mathrm{~J})$, which was previously shown to label RGCs that generate neurons that project axons to the corpus callosum, thalamus, and spinal cord (Guo et al., 2013). Strikingly, Fezf2-CreER ${ }^{T 2}$; RCE-GFP and Cux2-CreER ${ }^{T 2}$; RCE-GFP brains contained similar percentages of GFP; $\mathrm{Ct} ß$ double-positive cells $(10.3 \% \pm 0.9 \%$ L5 and $3.3 \% \pm 0.6 \% \mathrm{~L} 5$ 
Figure 4
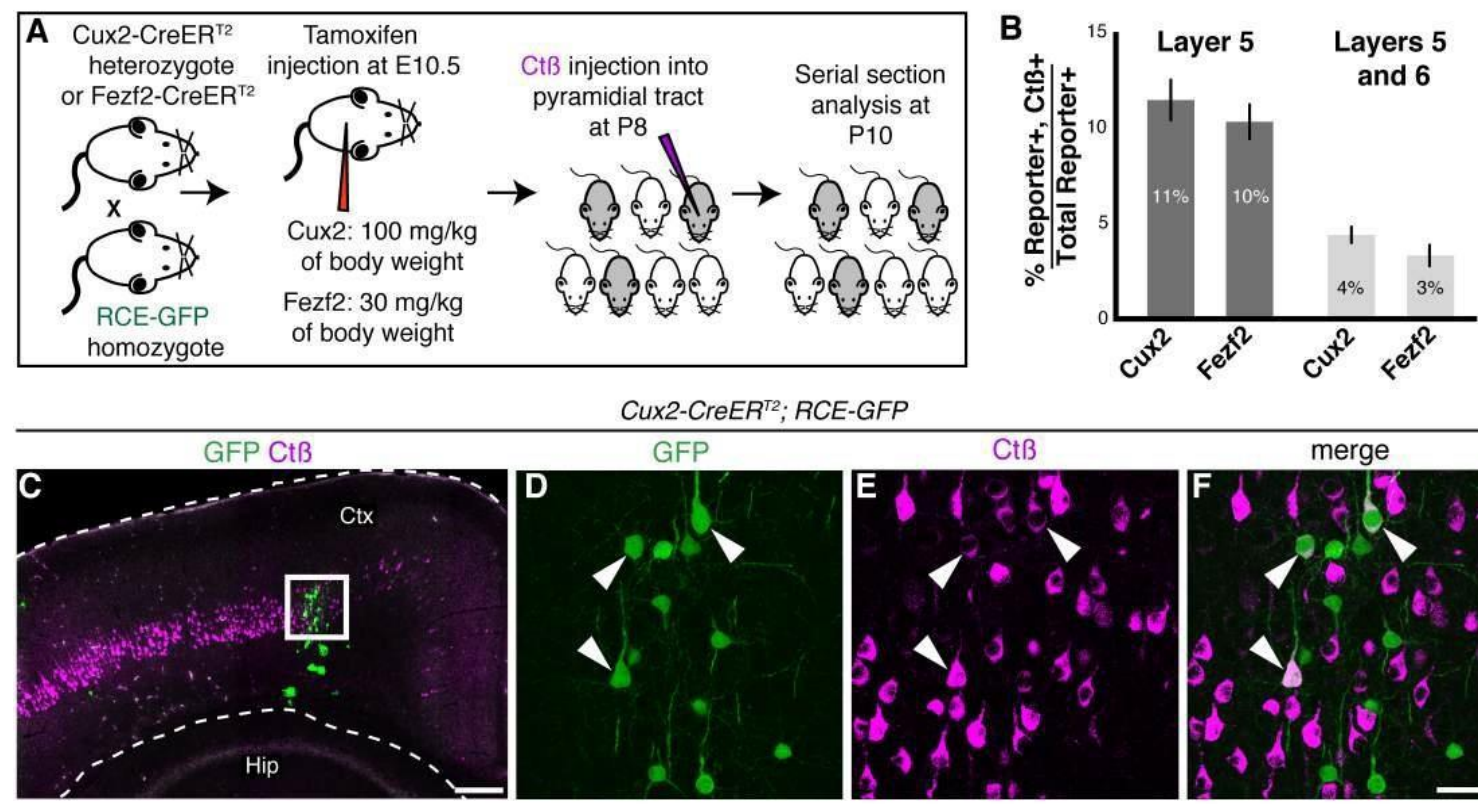

CUx2-CreER ${ }^{\text {T2}} ;$ RCE-GFP
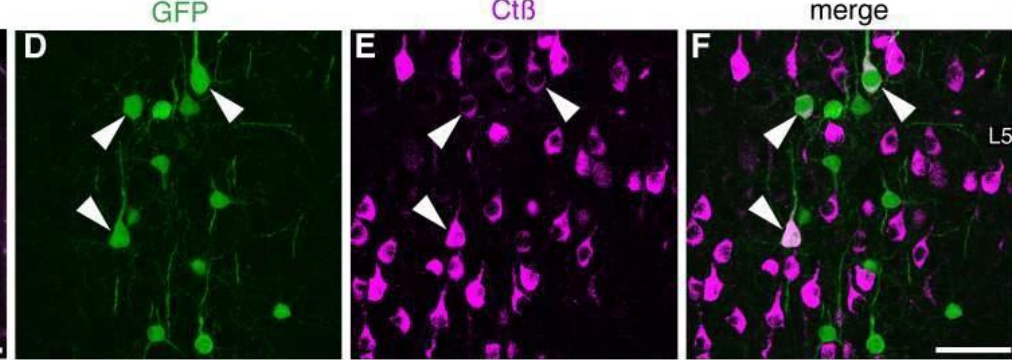

Fezf2-CreER $R^{\text {T2}} ;$ RCE-GFP
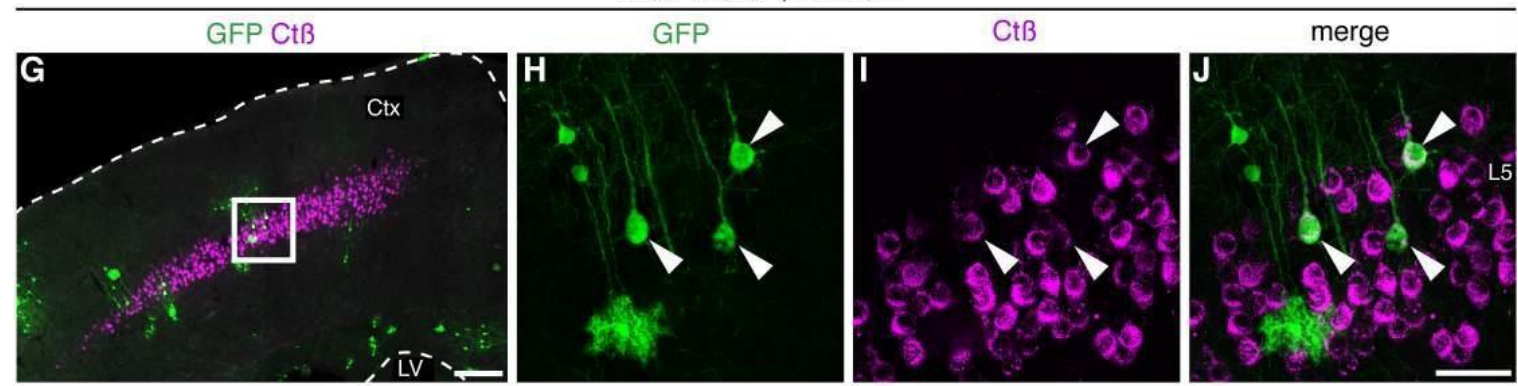

Figure 4. Retrograde labeling of the $\mathrm{Cux} 2^{+}$and Fezf2 $2^{+}$lineages. (A) Experimental setup. (B) Percentages of $\mathrm{GFP}^{+}$cells in layer 5 or in layers 5 and 6 that are also $\mathrm{Ct} ß$ positive. Error bars represent standard deviation $(\mathrm{n}=2$ brains for $\mathrm{Cux} 2$ and 6 brains for Fezf2). (C-F) Example of brain section from Cux2-CreER ${ }^{T 2}$; RCE-GFP mice that received TM at E10.5 and were injected with $\mathrm{Ct} ß$ at P8. Note the dense band of $\mathrm{Ct} ß$ labeling in layer 5. Panels (D-F) show an enlarged view of boxed region in (C). Arrowheads indicate $\mathrm{GFP}^{+}$cells originating from a Cux2 $2^{+} \mathrm{RGC}$ that extend subcerebral projections. (G-J) Example of brain section from Fezf2-CreER ${ }^{T 2}$; RCE-GFP mouse that received TM at E10.5 and was injected with $\mathrm{Ct} ß$ at P8. (H-J) Enlarged view of boxed regions shown in G. Arrowheads indicate GFP; Ctß double positive cells. Abbreviation: Ctx, cerebral cortex; Hip, hippocampus; LV, lateral ventricle. Scale bars: (C, G) $500 \mu \mathrm{m}$, (F, J) $100 \mu \mathrm{m}$. 
and L6 for Fezf2-CreER ${ }^{T 2}$ allele) (Figure 4B). These results confirm that both $\mathrm{Cux} 2^{+}$and Fezf $2^{+}$RGCs produce subcerebral projection neurons and demonstrate that early $\mathrm{Cux} 2^{+}$ RGCs are not lineage restricted to generate only corticocortical projection neurons.

\section{Discussion}

Our previous study demonstrated that at both the clonal and population levels Fezf $2^{+}$RGCs are multipotent and that at the population level Cux $2^{+} \mathrm{RGCs}$ are multipotent (Guo et al., 2013). This result suggested that either all Cux2 $2^{+}$RGCs are multipotent or, alternatively, $\mathrm{Cux} 2^{+} \mathrm{RGCs}$ might represent a heterogeneous population with different lineage potentials. Herein, our lineage analysis of individual $\mathrm{Cux} 2^{+} \mathrm{RGCs}$ provides evidence that most, if not all, $\mathrm{Cux} 2^{+} \mathrm{RGCs}$ are multipotent and generate diverse projection neuron subtypes located in cortical layers $2-6$. Further, we found that the laminar distribution and molecular expression profile of neurons generated from early $\mathrm{Cux}^{+}$RGCs was similar to that of neurons generated from early Fezf2 ${ }^{+}$RGCs (Figure 3), Nestin-CreER ${ }^{T 2+}$ RGCs (Franco et al., 2012), and Emx1-CreER ${ }^{T 2+}$ RGCs (Gao et al., 2014).

Using the Cux2-Cre and Cux2-CreER ${ }^{T 2}$ alleles, Franco et al. (2012) reported that $\mathrm{Cux}^{+}$RGCs generated only neurons and not glia. They also reported that among the progeny generated by E10.5 Cux2-CreER ${ }^{T 2}$-labeled RGCs, $90 \%$ of labeled cells were located in upper cortical layers while $10 \%$ were in deep layers. These data are significantly different from our previous and current results. By using two Cre reporter lines, RCE-GFP and Ai9, analyzing 6,258 lineage-traced cells, and reconstructing 43 RGC clones, we observed that at P10 roughly $10 \%$ of cells generated from E10.5 Cux2+ 
RGCs were astrocytes or oligodendrocytes. Moreover, we found that every E10.5 RGC clone we examined contained neurons located in both deep and upper cortical layers and that there was not a strong bias of the labeled cells to occupy upper cortical layers.

Both the current study and Gil-Sanz et al. (2015) demonstrate that Cux2 ${ }^{+}$RGCs generate a greater percentage of SATB2 ${ }^{+}$than $\mathrm{CTIP}^{+}{ }^{+}$neurons. However, Gil-Sanz et al. (2015) interpret the prevalence of SATB2 ${ }^{+}$neurons labeled by the Cux2-Cre and Cux2CreER ${ }^{T 2}$ alleles as evidence that $\mathrm{Cux} 2^{+} \mathrm{RGCs}$ are lineage restricted. SATB2 is expressed in a greater number of neocortical cells compared to CTIP2 (Figure S4; see also Figure 3E of Gil-Sanz et al. [2015]). Thus, it is not surprising that a multipotent RGC, which generates diverse subtypes of projection neurons, can produce a higher percentage of SATB2 ${ }^{+}$than $\mathrm{CTIP}^{+}$progeny. This highlights the need to define projection neuron subtype identity using multiple parameters, including additional molecular markers and axonal projections. Toward this, we found that a similar percentage of neurons with subcerebral projections were born from $\mathrm{Cux} 2^{+} \mathrm{RGCs}$ and Fezf2 ${ }^{+}$RGCs labeled at E10.5 (Figure 4).

Gil-Sanz et al. (2015) attribute the difference in results between experiments performed in the Müller laboratory (Franco et al., 2012 and Gil-Sanz et al., 2015) and our work (Guo et al., 2013 and current study) to breeding strategy and genetic background. The authors propose that the low recombination efficiency we observe in $\mathrm{Cu} 2 \mathrm{2}-\mathrm{CreER}{ }^{T 2}$ mice at E10.5, using a TM dosage of $100 \mathrm{mg} / \mathrm{kg}$ of body weight, is an artifact of genetic background. Furthermore, they suggest that our lineage analysis results with the Cux2CreER ${ }^{T 2}$ allele are highly influenced by genetic background. Gil-Sanz et al. (2015) 
report that the $\mathrm{Cux2}-\mathrm{CreER}{ }^{T 2}$ allele previously induced more widespread recombination at a TM dosage of $50 \mathrm{mg} / \mathrm{kg}$ when compared to the current study. We disagree; our interpretation of Figure S2 from Franco et al. (2012) is that sparse recombination was prevalent at this dosage, similar to results from our laboratory. Moreover, in Gil-Sanz et al. (2015), the authors injected 4-hydroxytamoxifen (4-OHT) at a dosage of $50 \mathrm{mg} / \mathrm{kg}$ of body weight (or $1 \mathrm{mg} / 20 \mathrm{~g}$ ) to achieve sparse labeling of E10.5 Cux $2^{+}$RGCs. However, 4-OHT has a much greater affinity $(50 x-100 x)$ than TM for binding estrogen receptors and is significantly more potent at inducing recombination (Hans et al., 2009; Malet et al., 1988). Thus, the recombination efficiency of the $\mathrm{Cux2}-\mathrm{CreER}^{T 2}$ allele in studies from the Müller laboratory does not appear to be significantly higher than that observed in our laboratory (compare Figures 1 and 2 in the current study with Figures 3 and S3D-S3I of Gil-Sanz et al. [2015]).

One explanation for the divergent conclusions reached by our work and that of Franco et al. (2012) and Gil-Sanz et al. (2015) is that the latter two studies relied heavily on Cux2-Cre mice, which are not suitable for lineage analysis of neocortical RGCs. Here we present evidence that explains why the lineage analysis of neocortical RGCs is confounded by the complex temporal expression pattern of the Cux2-Cre allele. The recombinase activity of CRE driven from the $C u x 2$ locus is constitutively active and thus recombination can occur in RGCs, basal progenitor cells, or postmitotic neurons. Accordingly, a reporter ${ }^{+}$neuron in the cortical plate cannot be assumed to have originated from a $\mathrm{Cux} 2^{+} \mathrm{RGC}$. Within the neocortex, $\mathrm{Cux} 2$ is preferentially expressed in upper cortical layers. Therefore, a higher percentage of reporter-expressing cells within upper 
versus deep cortical layers in a small subset of cortical areas (e.g. the anterior cingulate area) in $\mathrm{Cux2-Cre}$ mice is not unexpected based upon the expression pattern of $\mathrm{Cux2}$, and does not indicate that $\mathrm{Cux} 2^{+} \mathrm{RGCs}$ preferentially generate upper-layer neurons.

Recently, Gao et al. (2014) performed lineage analyses of individual RGCs using MADM. Through low-density labeling of RGCs with the Emx1-CreER ${ }^{T 2}$ and NestinCreER ${ }^{T 2}$ alleles, they reported that $100 \%$ of clones generated from RGCs labeled at E10.5 contained neurons that occupied cortical layers 2-6. Notably, despite the differences in recombination efficiency between the MADM strategy and our current study, the average numbers of cells per clone and rostral-caudal dispersion of cells in the clones are similar between the two studies. Moreover, by analyzing subtype-specific markers, Gao et al. (2014) found that individual clones contained cells expressing markers for multiple subclasses of neocortical projection neurons. Combined with the current study, this work provides important evidence for the prevalence of multipotent RGCs within the early neocortical progenitor pool.

Collectively, our results demonstrate that early $\mathrm{Cux} 2^{+}$and Fezf2 ${ }^{+} \mathrm{RGCs}$ are multipotent neocortical progenitors. However, these findings do not exclude the existence of fate-restricted RGCs during early cortical development. Rather, they indicate that neither Fezf2 nor Cux2 expression alone is sufficient to identify these cells and that appropriate molecular or genetic markers await future investigation. 


\section{Experimental Procedures}

All experiments were carried out in accordance with the protocols approved by the IACUC at University of California at Santa Cruz and institutional and federal guidelines. The day of vaginal plug detection was designated as E0.5. The day of birth was designated as P0. Immunohistochemistry was performed as previously described (Eckler et al., 2011). Extended experimental details are included in Supplemental Experimental Procedures. 


\section{Supplemental Figures}

Figure S1

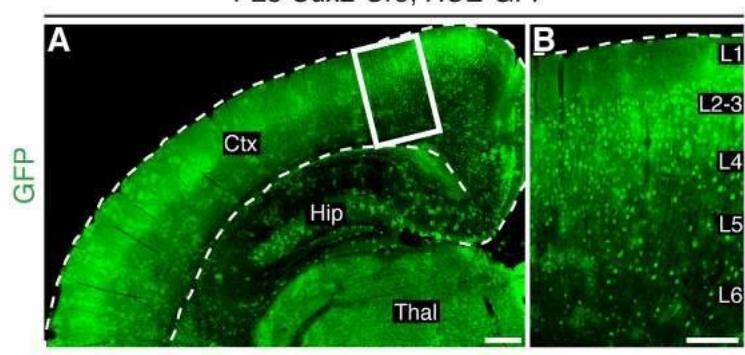

P58 Cux2-Cre; Ai14

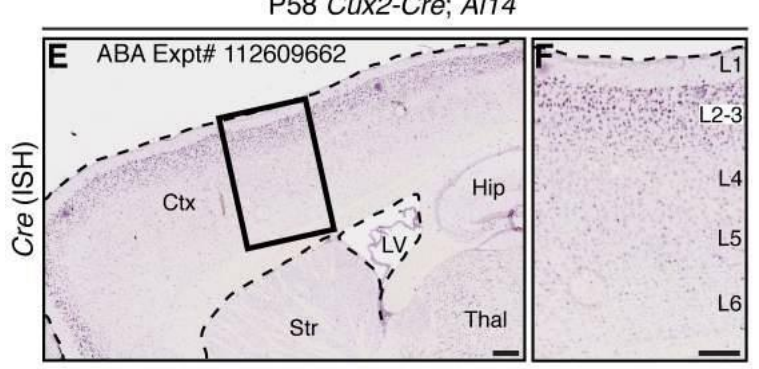

P56 Cux2-Cre; Ai14

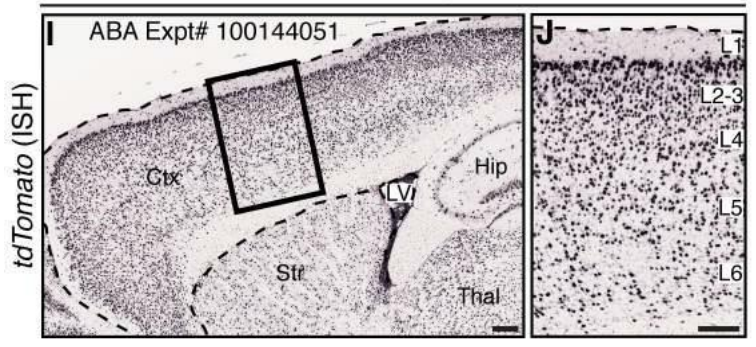

P56 Cux2-Cre; Ai14
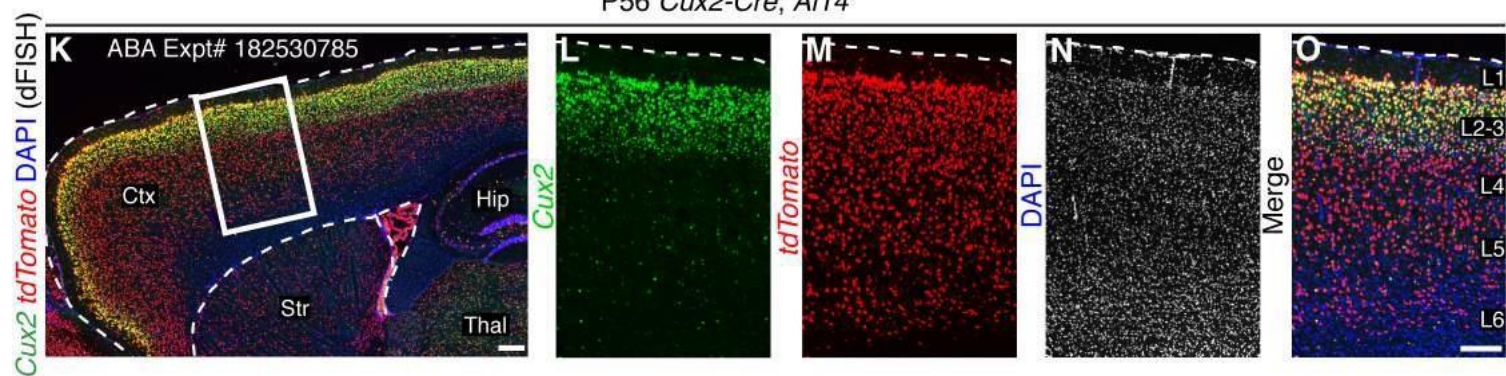

Supplemental Figure 1. Related to Figure 1. The Cux2-Cre allele does not report the origin of neocortical projection neurons. (A, B) P28 Cux2-Cre; RCE-GFP brain section. (C-O) In situ hybridization data generated by the Allen Brain Institute and freely available online at the Allen Brian Atlas. (C-D) In situ hybridization (ISH) showing Cux2 expression in a P56 wild-type brain. (E, F) In situ hybridization showing Cre expression in a P58 Cux2-Cre; Ail4 brain. (G-J) In situ hybridization showing tdTomato expression in the cortex of a P56 Cux2-CreER ${ }^{T 2}$; Ail4 mouse which received a once-daily tamoxifen injection from P45 to P49 (G-H) or a P56 Cux2Cre; Ail4 brain (I-J). Higher magnification images of the boxed regions in (A), (C), (E), (G), (I) are shown in (B), (D), (F), (H), and (J), respectively. (K-O) Double fluorescent in situ hybridization showing Cux2 (green) and tdTomato (red) expression in a P56 Cux2Cre; Ail4 brain. DAPI staining for cell nuclei is shown in blue. Higher magnification images of the boxed area in (K) are shown in (LO). Abbreviations: Ctx, cerebral cortex; Hip, hippocampus; LV, lateral ventricle; Str, striatum; Thal, thalamus. Scale bars: (A, C, E, G, I, K) $500 \mu \mathrm{m}$, (B, D, F, H, J, Q) $250 \mu \mathrm{m}$. Image credit: (C-O) Allen Brain Institute. 
Figure S2
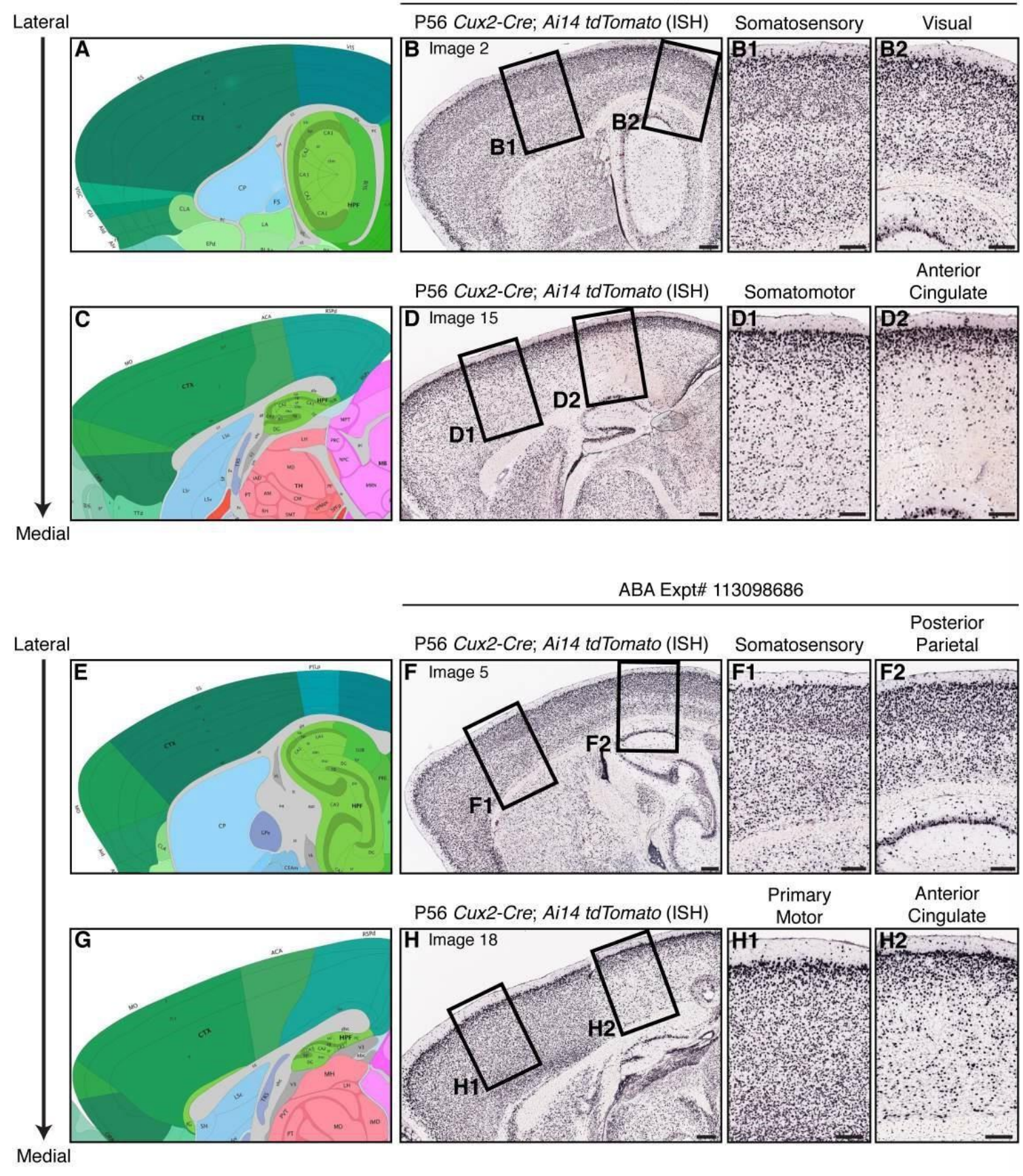

ABA Expt\# 100144051

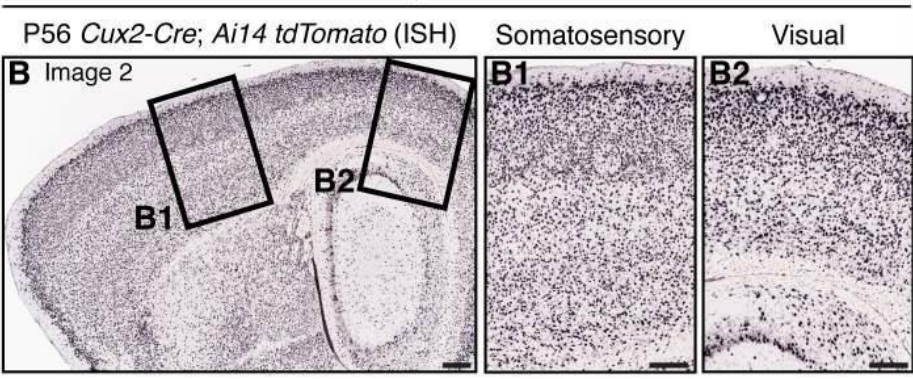

Anterior

P56 Cux2-Cre; Ai14 tdTomato (ISH) D Image 15

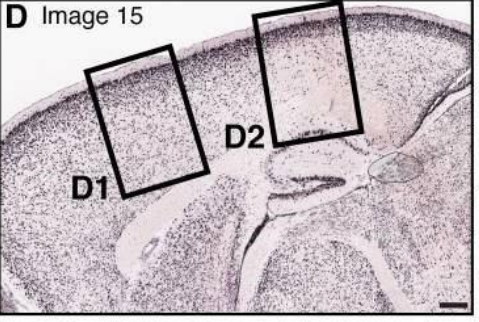

Somatomotor

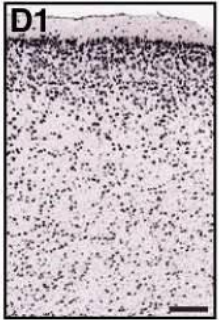

\section{D2}

miscait

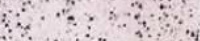

ivisar: 


\begin{tabular}{|c|c|c|c|c|c|}
\hline & Clone type & \multicolumn{2}{|c|}{ Clone size } & Laminar distribution & $\begin{array}{l}\text { Number of } 50 \mu \mathrm{m} \\
\text { sections spanned }\end{array}$ \\
\hline $\begin{array}{l}\text { Cux2+ } \\
n=43\end{array}$ & $\begin{array}{l}\text { Neuron only: } \\
13(30 \%) \\
\text { Neuron + glia: } \\
30(70 \%)\end{array}$ & $\begin{array}{r}\text { Mean: } 82.8+/-54.5 \\
\text { Cell number per clone: } \\
1 \text { to } 25 \\
26 \text { to } 50 \\
51 \text { to } 75 \\
76 \text { to } 100 \\
101 \text { to } 125 \\
126 \text { to } 150 \\
151+\end{array}$ & 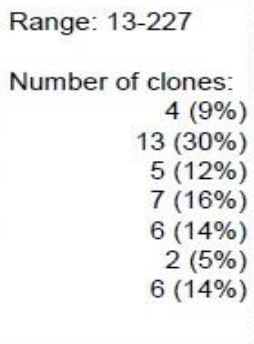 & $\begin{array}{l}\text { Total cells: } 3,562 \\
\text { UL } 1,920(54 \%) \\
\text { DL } 1,642(46 \%) \\
\text { Neurons: } 3,188(90 \%) \\
\text { UL } 1,743(55 \%) \\
\text { DL } 1,445(45 \%) \\
\text { Glia: } 374(10 \%) \\
\text { UL } 177(47 \%) \\
\text { DL } 197(53 \%)\end{array}$ & $\begin{array}{l}\text { Range: } 2-12 \\
\text { Average: } 7\end{array}$ \\
\hline $\begin{array}{l}\text { Fezf2+ } \\
n=46\end{array}$ & $\begin{array}{l}\text { Neuron only: } \\
13(28 \%) \\
\text { Neuron + glia: } \\
33(72 \%)\end{array}$ & $\begin{array}{r}\text { Mean: } 67.39+/-41.52 \\
\text { Cell number per clone: } \\
1 \text { to } 25 \\
26 \text { to } 50 \\
51 \text { to } 75 \\
76 \text { to } 100 \\
101 \text { to } 125 \\
126 \text { to } 150 \\
151+\end{array}$ & $\begin{array}{l}\text { Range: } 13-242 \\
\begin{array}{r}\text { Number of clones: } \\
5(11 \%) \\
14(30 \%) \\
10(22 \%) \\
10(22 \%) \\
3(7 \%) \\
2(4 \%) \\
2(4 \%)\end{array}\end{array}$ & $\begin{array}{l}\text { Total cells: } 3,100 \\
\text { UL } 1,710(55 \%) \\
\text { DL } 1,390(45 \%) \\
\text { Neurons: } 2,739(88 \%) \\
\text { UL } 1,542(56 \%) \\
\text { DL } 1,197(44 \%) \\
\text { Glia: } 361(12 \%) \\
\text { UL } 168(47 \%) \\
\text { DL } 193(53 \%)\end{array}$ & $\begin{array}{l}\text { Range: } 2-11 \\
\text { Average: } 6\end{array}$ \\
\hline
\end{tabular}

Supplemental Table 1. Summary of fully reconstructed $\mathrm{Cux} 2^{+}$and $\mathrm{Fezf} 2^{+}$clones analyzed in this study. Mean number of cells per clone is reported as $\%$ - standard deviation. Abbreviations: DL, deep cortical layers (layers 5 and 6); UL, upper cortical layers (layers 2-4). 


\section{REFERENCES}

Alcamo, E.A., Chirivella, L., Dautzenberg, M., Dobreva, G., Farinas, I., Grosschedl, R., and McConnell, S.K. (2008). Satb2 regulates callosal projection neuron identity in the developing cerebral cortex. Neuron 57, 364-377.

Bedogni, F., Hodge, R.D., Elsen, G.E., Nelson, B.R., Daza, R.A., Beyer, R.P., Bammler, T.K., Rubenstein, J.L., and Hevner, R.F. Tbr1 regulates regional and laminar identity of postmitotic neurons in developing neocortex. Proc Natl Acad Sci U S A 107, 1312913134.

Britanova, O., de Juan Romero, C., Cheung, A., Kwan, K.Y., Schwark, M., Gyorgy, A., Vogel, T., Akopov, S., Mitkovski, M., Agoston, D., et al. (2008). Satb2 is a postmitotic determinant for upper-layer neuron specification in the neocortex. Neuron 57, 378-392.

Chen, B., Wang, S.S., Hattox, A.M., Rayburn, H., Nelson, S.B., and McConnell, S.K. (2008). The Fezf2-Ctip2 genetic pathway regulates the fate choice of subcortical projection neurons in the developing cerebral cortex. Proc Natl Acad Sci U S A 105, 11382-11387.

Cubelos, B., Sebastian-Serrano, A., Beccari, L., Calcagnotto, M.E., Cisneros, E., Kim, S., Dopazo, A., Alvarez-Dolado, M., Redondo, J.M., Bovolenta, P., et al. (2010). Cux 1 and Cux 2 regulate dendritic branching, spine morphology, and synapses of the upper layer neurons of the cortex. Neuron 66, 523-535.

Eckler, M.J., McKenna, W.L., Taghvaei, S., McConnell, S.K., and Chen, B. (2011). Fezf1 and Fezf2 are required for olfactory development and sensory neuron identity. J Comp Neurol 519, 1829-1846.

Franco, S.J., Gil-Sanz, C., Martinez-Garay, I., Espinosa, A., Harkins-Perry, S.R., Ramos, C., and Müller, U. (2012). Fate-restricted neural progenitors in the mammalian cerebral cortex. Science 337, 746-749.

Franco, S.J., Martinez-Garay, I., Gil-Sanz, C., Harkins-Perry, S.R., and Müller, U. (2011). Reelin regulates cadherin function via Dab1/Rap1 to control neuronal migration and lamination in the neocortex. Neuron 69, 482-497.

Franco, S.J., and Müller, U. (2013). Shaping our minds: stem and progenitor cell diversity in the mammalian neocortex. Neuron 77, 19-34. 
Gao, P., Postiglione, M.P., Krieger, T.G., Hernandez, L., Wang, C., Han, Z., Streicher, C., Papusheva, E., Insolera, R., Chugh, K., et al. (2014). Deterministic progenitor behavior and unitary production of neurons in the neocortex. Cell 159, 775-788.

Gil-Sanz, C., Espinosa, A., Fregoso, S.P., Bluske, K.K., Cunningham, C.L., MartinezGaray, I., Zeng, H., Franco, S.J., and Müller, U. (2015) Matters Arising: Lineage tracing using Cux2-Cre and Cux2-CreER ${ }^{T 2}$ mice. Neuron XX, XXX-XXX.

Greig, L.C., Woodworth, M.B., Galazo, M.J., Padmanabhan, H., and Macklis, J.D. (2013). Molecular logic of neocortical projection neuron specification, development and diversity. Nat Rev Neurosci 14, 755-769.

Guo, C., Eckler, M.J., McKenna, W.L., McKinsey, G.L., Rubenstein, J.L., and Chen, B. (2013). Fezf2 expression identifies a multipotent progenitor for neocortical projection neurons, astrocytes, and oligodendrocytes. Neuron 80, 1167-1174.

Han, W., Kwan, K.Y., Shim, S., Lam, M.M., Shin, Y., Xu, X., Zhu, Y., Li, M., and Sestan, N. (2013) TBR1 directly represses Fezf2 to control the laminar origin and development of the corticospinal tract. Proc Natl Acad Sci U S A 108, 3041-3046.

Han, W., and Sestan, N. (2013). Cortical projection neurons: sprung from the same root. Neuron 80, 1103-1105.

Hevner, R.F., Shi, L., Justice, N., Hsueh, Y., Sheng, M., Smiga, S., Bulfone, A., Goffinet, A.M., Campagnoni, A.T., and Rubenstein, J.L. (2001). Tbr1 regulates differentiation of the preplate and layer 6. Neuron 29,353-366.

Madisen, L., Zwingman, T.A., Sunkin, S.M., Oh, S.W., Zariwala, H.A., Gu, H., Ng, L.L., Palmiter, R.D., Hawrylycz, M.J., Jones, A.R., et al. (2010). A robust and high-throughput Cre reporting and characterization system for the whole mouse brain. Nat Neurosci 13, 133-140.

McKenna, W.L., Betancourt, J., Larkin, K.A., Abrams, B., Guo, C., Rubenstein, J.L., and Chen, B. (2011). Tbr1 and Fezf2 regulate alternate corticofugal neuronal identities during neocortical development. J Neurosci 31, 549-564.

Miyoshi, G., and Fishell, G. (2012). Dynamic FoxG1 expression coordinates the integration of multipolar pyramidal neuron precursors into the cortical plate. Neuron 74 , 1045-1058. 
Molyneaux, B.J., Arlotta, P., Hirata, T., Hibi, M., and Macklis, J.D. (2005). Fezl is required for the birth and specification of corticospinal motor neurons. Neuron 47 , 817831.

Sousa, V.H., Miyoshi, G., Hjerling-Leffler, J., Karayannis, T., and Fishell, G. (2009). Characterization of Nkx6-2-derived neocortical interneuron lineages. Cereb Cortex 19 Suppl 1, i1-10. 


\section{CHAPTER III}

\section{Conclusion}

The progressive lineage restriction theory is a decades-old model that posits that RGCs become gradually restricted in their ability to generate neuronal subtypes as cortical development progresses. Initially, a RGC can generate deep layer corticothalamic (L6), corticospinal (L5) neurons, and upper layer (L2-4) callosal projection neurons. As development proceeds, RGCs eventually loses its multipotent ability, able to generate only L5 and above, L4 and above, and then finally only the superficial L2/3. This theory was recently challenged, suggesting a RGC subpopulation marked by $\mathrm{Cux} 2^{+}$expression is fated to become exclusively upper layer (L2-4) neurons at an early stage (Franco et al. 2012). Using similar methods, we were unable to replicate their results, and instead found that the RGCs marked by Cux 2 expression follow the progressive lineage restriction model.

Our work provides evidence that early $\mathrm{Cux} 2^{+} \mathrm{RGCs}$ are multipotent progenitors capable of generating neurons, astrocytes, and oligodendrocytes. These progenies will populate throughout cortical layers 2-6. We did not find any evidence of fate-restricted early neocortical progenitors; however, we cannot exclude the possibility of their existence. Simply put, there are numerous untested transcription factors and only a few available transgenic $C r e-E R^{T 2}$ lines. A potential candidate may exist. However, we found no evidence that the lineages of $\mathrm{Cux} 2^{+}$RGCs support this theory, and a fate-restricted population of RGCs remains to be seen. 
We believe that our different results to Franco et al. may be attributable to methodology and analysis. Specifically, Franco et al.'s use of a constitutive Cre is not ideal for lineage tracing analysis as it can produce a false positive. Cre activates under concurrent expression of a specific promoter. While we agree that a subset of dorsal RGCs express Cux2 at an early embryonic age, Cux 2 is also expressed in the post-mitotic projection neurons within the upper layers. This will lead to unintended recombination. The main point of contention is that Cux2-Cre activation may occur in cells that (1) did not originate from an E10.5 $\mathrm{Cux} 2^{+} \mathrm{RGC}$ and (2) gives a skewed result due to postnatal Cux2 expression.

To the point, the in situ hybridization data Franco et al. 2012 presented shows low expression of Cux2 mRNA at the VZ of E14.5 mice and high expression in the upper layers of P7 mice (Fig. II A-B). They interpret this as a causative progression, with the progenitor and progeny both expressing Cux2 at different times. However, they did not see this as a possible conflict when using the constitutive Cux2-Cre line. Cells that do not necessarily originate from $\mathrm{Cux} 2^{+} \mathrm{RGCs}$ can also express $\mathrm{Cux} 2$ at a mature stage, as shown from our study using Fezf2-CreER ${ }^{T 2}$ (Fig IV A-J). Already, this raises questions for the immediate following data (Fig. II C), which shows a high level of Ai9 recombination at $\mathrm{P} 10$. Since their own data shows that upper layer neurons have a high level of intrinsic $\mathrm{Cux} 2$ expression, this would cause recombination in cells that may not necessarily originate from E10.5 Cux2+ RGCs. This Cux 2 activation would drive expression of Cre and cause recombination in cells whether or not they were generated from $\mathrm{Cux} 2^{+} \mathrm{RGCs}$ at E10.5. This inadvertent Cre activation will lead to a false positive. 
To address the problems with using constitutive Cre, we used tamoxifen-inducible $\mathrm{CreER}^{T 2}$ to produce a clonal-level recombination in early embryonic mice. This is to avoid unintentional Cre-mediated recombination in post-mitotic cells. Furthermore, TM activates the reporter within a short window (24-48 hours), providing a high degree of confidence that only cells activated within that time frame are marked. We then serially reconstructed the brain at P21 from rostral to caudal in order to fully image individual RGC clones and its progeny. Our analysis indicates every single clone analyzed of both the Cux2 and Fezf2 lineage produces neurons and glia that span all the layers of the cerebral cortex.

In their Matters Arising response (Gil-Sanz et al. 2015), 4-hydroxytamoxifen (4OHT) was used to induce a sparse labeling of cells at a dosage of $50 \mathrm{mg} / \mathrm{kg} 4-\mathrm{OHT}$. This is unusual, as 4-OHT, the metabolically active form of estrogen, has an approximately 50-100 fold higher binding affinity to estrogen receptors than tamoxifen. This would equate to a dosage of at least roughly $2500 \mathrm{mg} / \mathrm{kg}$ tamoxifen. Dosage is important because it is roughly proportional to the amount of reporter activation. The higher the dose, the more RGCs are labelled, which should result in a population-level recombination rather than a clonal-level. For comparison, we achieved clonal-level recombination in $\mathrm{Cux2}-\mathrm{CreER}^{T 2}$ using $100 \mathrm{mg} / \mathrm{kg}$ tamoxifen.

This issue is further compounded by an initially reported low Cux2 in situ expression from Franco et al. (Fig IIB). If RGCs all produced clones of similar size, then these few $\mathrm{Cux2}^{+}$RGCs will have to generate a large quantity exclusively of upper-layer neurons during mid-corticogenesis (Fig IIC). They provide no data for the intermediary 
time points. Given their specific dosage, we should expect a population-level recombination as shown in Franco et al. Instead, they purportedly achieved a clonal-level recombination with an even higher dose.

The Franco paper's analysis using in utero electroporation of the FLEx plasmid likewise also yields ambiguous results (Fig III. A). The method does not specifically label RGCs, as electroporated cells that take up the plasmid are of indeterminate origin. For example, they may be IPCs of the SVZ or even nascent neurons migrating. Furthermore, recombination of the FLEx plasmid may happen in post-mitotic neurons, especially in the upper-layer Cux2-expressing neurons. This experiment indicates that neurons migrating into the upper layers eventually express Cux2. This is hardly surprising given that even Cux2-negative E10.5 RGCs can produce progeny that migrate to, and eventually express, upper layer markers such as Cux 1 or Cux2. Indeed, analysis using TM E10.5 Fezf2-CreER ${ }^{T 2}$ reveals a high level of Cux1 expression in generated cells that migrate to the upper layers (Fig. IV A-B, Fig. 3 G).

We also utilized a population-level analysis by examining the majority of recombined cells of the brain. Our numbers indicate approximately 55\% upper layer to 45\% deeper layer distribution in both the $\mathrm{Cux}_{2}{ }^{+}$and Fezf2 $2^{+}$E10.5 RGC progeny. Interestingly, these numbers are in accord with those generated by the Müller lab when they used a Nestin-Cre system as a control for their experiments (Fig. III. H). Nestin is a generic marker for neural progenitor cells. Our data indicates that the lineages of $\mathrm{Cux}^{+}$ RGCs are analogous to those of RGCs labeled by Nestin-Cre, both of which are consistent with the progressive lineage restriction model. 
Moreover, analysis revealed that a large portion of cells originating from the Cux2 lineage express molecular markers that are deep layer-specific. These markers include DARPP-32 (L6), Tbr1 (L6), and Ctip2 (L5). Further examination confirms that they can also generate astrocytes and oligodendrocytes by staining for GFAP and Olig2, respectively. All this taken together suggests that $\mathrm{Cux}_{2}{ }^{+} \mathrm{RGCs}$ are multipotent progenitors and follow the lineage restriction model of cortical development.

While we cannot discount the existence of early fate-restricted progenitors, we do not believe that $\mathrm{Cux} 2^{+}$RGCs provide any support for such RGCs. We contend that $\mathrm{Cux}^{+}$ RGCs are actually multipotent progenitors.

\section{Future Directions}

The lineages of cortical RGCs remain being heatedly contended. However, with currently available technology and databases, it is an important issue that may not take long to have an answer.

Our analysis showed that early RGCs are multipotent progenitors. It remains to be discovered exactly when, and by which specific mechanisms, a migrating neuron determines its final laminar position and identity. In order to address cell fate determination, our current work will investigate two possibilities: the RGC and IPC intermediate progenitor lineage potential at different time points.

For the RGC, we will continue clonal analysis at different time points to determine where and when these neurons become fate-restricted. We will examine their distribution throughout the cortex, and derive a census of the clone types produced. 
We are also interested to see if and when IPCs determine their identity, which are marked by Tbr2 expression. We are investigating the following stage of RGC differentiation to determine whether or not lineage restriction occurs. Altogether, our future studies hope to elucidate the characteristics of RGCs and their subsequent progeny. 


\section{REFERENCES}

1. Aggelopoulos, N.C. Perceptual inference. Neurosci Biobehav Rev. August 2015. $55: 375-92$

2. Anderson, S.A., Eisenstat, D.D., Shi, L., Rubenstein, J.L.R. Interneuron Migration from Basal Forebrain to Neocortex: Dependence on Dlx Genes. Science. 17 October 1997. 278(5337):474-6

3. Angevine, J.B., Sidman, R.L. Autoradiographic study of cell migration during histogenesis of cerebral cortex in mouse. Nature. 1961. 192:766-68.

4. Bultje, R.S., Castaneda-Castellanos, D.R., Jan, L.Y., Jan, Y.N, Kriegstein, A.R., Shi, S.H. Mammalian Par3 Regulates Progenitor Cell Asymmetric Division via Notch Signaling in the Developing Neocortex. Neuron 63. July 30, 2009. 189-202

5. Chen, B., Schaevitz, L.R., McConnell S.K. FezI regulates the differentiation and axon targeting of layer 5 subcortical projection neurons in cerebral cortex. PNAS. 2005. Pp. 17184-89

6. Chen, B., Wang, S.S., Hattox, A.M., Rayburn, H., Nelson, S.B., McConnell, S.K. The Fezf2-Ctip2 genetic pathway regulates the fate choice of subcortical projection neurons in the developing cerebral cortex. Proc Natl Acad Sci U S A. 2008 Aug 12; 105(32):11382-7

7. Chen, J.G., Rasin, M.R., Kwan, K.Y., Sestan, N. Zfp312 is required for subcortical axonal projections and dendritic morphology of deep-layer pyramidal neurons of the cerebral cortex. PNAS 2005. Pp. 17792-97

8. DeBoer, E.M., Kraushar, M.L., Hart, R.P., Rasin, M.R. Post-transcriptional regulatory elements and spatiotemporal specification of neocortical stem cells and projection neurons. Neuroscience. 2013 September 17; 0:499-528

9. Franco, S.J., Gil-Sanz, C., Martinez-Garay, I., Espinosa, A., Harkins-Perry, S.R., Ramos, C., Müller, U. Fate-Restricted Neural Progenitors in the Mammalian Cerebral Cortex. Science. 10 August 2012. 337(6095): 746-749

10. Friedrich, G., Soriano, P. Promoter traps in embryonic stem cells: a genetic screen to identify and mutate developmental genes in mice. Genes Dev. 1991 Sep; 5(9):151323 
11. Fuentealba, L.C., Rompani, S.B., Parraguez, J.I., Obernier, K., Romero, R., Cepko, C.L., Alvarez-Buylla, A. Embryonic Origin of Postnatal Neural Stem Cells. Cell. 18 June 2015. 161: 1644-1655 12. Greig, L.C., Woodworth, M.B., Galazo, M.J., Padmanabhan, H., and Macklis, J.D. (2013). Molecular logic of neocortical projection neuron specification, development and diversity. Nat Rev Neurosci 14, 755-769.

13. Guo, C., Eckler, M.J., McKenna, W.L., McKinsey, G.L., Rubenstein, J.L.R., Chen, B. Fezf2 Expression Identifies a Multipotent Progenitor for Neocortical Projection Neurons, Astrocytes, and Oligodendrocytes. Neuron. 4 Dec. 2013. (80) 5:1167-74

14. Hack, I., Bancila, M., Loulier, K., Carroll, P., Cremer, H. Reelin is a detachment signal in tangential chain-migration during postnatal neurogenesis. Nature Neuroscience. 2002. 5:939-45

15. He, S., Li, Z., Ge, S., Yu, Y.C., Shi, S.H. Inside-Out Radial Migration Facilitates Lineage-dependent Neocortical Microcircuit Assembly. Neuron 86. June 3, 2015. $1159-1166$

16. Hicks, S.P., D'Amato, C.J. Motor-sensory cortex-corticospinal system and developing locomotion and placing in rats. Am J Anat. 1975 May; 143(1):1-42

17. Hirata-Fukae, C., Hirata, T. The Zinc Finger Gene Fezf2 is required for the development of excitatory neurons in the basolateral complex of the amygdala. Developmental Dynamics. 2014. 00:000-000

18. Jang, SH. Recovery mechanisms of somatosensory function in stroke patients: implications of brain imaging studies. Neurosci. Bull. 2013 June;29(3):366-72

19. Kawai, R., Markman, T., Poddar, R., Ko, R., Fantana, A.L., Dhawale, A.K., Kampff, A.R., Olveczky, B.P. Motor Cortex Is Required for Learning but Not for Executing a Motor Skill. Neuron. 6 May 2015. (86)3:800-812

20. Kumamoto, T., Hanashima, C. Neuronal subtype specification in establishing mammalian neocortical circuits. Neurosci Res. 2014 Sep; 86:37-49

21. Leone, D.P., Genoud, S., Atanasoski, S., Grausenburger, R., Berger, P., Metzger, D., Macklin, W.B., Chambon, P., Suter, U. Tamoxifen-inducible glia-specific Cre mic for somatic mutagenesis in oligodendrocytes and Schwann cells. Mol. and Cell. Neurosci. 2003 April. (22) 4:417-556 
22. Lizen, B., Claus, M., Jeannotte, L., Rijli, F.M., Gofflot, F. Perinatal induction of Cre recombination with tamoxifen. Transgenic Research. 22 Sep 2015. Pp 1-13

23. Lledo, P.M., Merkle, F.T., Alvarez-Buylla, A. Origin and function of olfactory bulb interneuron diversity. Trends in Neurosciences. 5 July 2008. Vol 31: 392-400

24. Malet, C., Gompel, A., Spritzer, F., Bricout, N., Yaneva, H., Mowszowicz, I., Kuttenn, F., Mauvais-Jarvis, F. Tamoxifen and hydroxytamoxifen isomers versus estradiol effects on normal human breast cells in culture. Cancer Res. 1988 Dec 15:48(24 Pt 1):7193-9

25. Markram, H. Toledo-Rodriguez, M., Wang, Y., Gupta, A., Silberberg, G., Wu, C. Interneurons of the neocortical inhibitory system. Nat Rev Neurosci. Oct 2004. 5(10):793-807

26. Marin, O., Müller, U. Lineage origins of GABAergic versus glutamatergic neurons in the neocortex. Current Opinion in Neurobiology. 2014, 26:132-141

27. McConnell, S.K. Migration and differentiation of cerebral cortical neurons after transplantation into the brains of ferrets. Science. 1985 Sep 20; 229(4719):1268-71

28. McConnell, S.K. Constructing the cerebral cortex: neurogenesis and fate determination. Neuron. 1995 Oct; 15(4):761-8.

29. Molyneaux, B.J., Arlotta, P., Menezes, J.R.L., Macklis, J.D. Neuronal subtype specification in the cerebral cortex. Nature Rev Neurosci. Vol 8, June 2007. 427-438

30. Nagy, A. Cre recombinase: the universal reagent for genome tailoring. Genesis. 2000 Feb: 26(2):99-109

31. Nakahira, E., Kagawa, T., Shimizu, T., Goulding, MD., Ikenaka, K. Direct evidence that ventral forebrain cells migrate to the cortex and contribute to the generation of cortical myelinating oligodendrocytes. Dev Biol. 2006 Mar 1; 291(1):123-31

32. Noctor, S.C., Martinez-Cerdeño, V., Kriegstein, A.R. Distinct behaviors of neural stem and progenitor cells underlie cortical neurogenesis. J Comp Neurol. 2008 May $1 ; 508(1): 28-44$

33. Pleger, B., Villringer, A. The human somatosensory system: from perception to decision making. Prog Neurobiol. 2013 Apr;103:76-97 
34. Rakic, P. Guidance of neurons migrating to the fetal monkey neocortex. Brain Res. 1971 Oct 29;33(2):471-6

35. Sato, M., Yasuoka, Y., Kodama, H., Watanabe, T., Miyazaki, J.I., Kimura, M. New approach to cell lineage analysis in mammals using the Cre-loxP system. Mol Reprod Dev. 2000 May: 56(1):34-44

36. Sauer, B., Henderson, N. Site-specific DNA recombination in mammalian cells by the Cre recombinase of bacteriophage P1. Proc Natl Acad Sci. July 1988. 85(14):516670.

37. Selemon, L.D., Zecevic, N. Schizophrenia: a tale of two critical periods for prefrontal cortical development. Transl Psychiatry. 2015 Aug 18;5:e623

38. Sternberg, N., Hamilton, D. Bacteriophage P1 site-specific recombination: I. Recombination between loxP sites. J Mol Biol. 1981 Aug 25; 150(4):467-86

39. Stoodley, C.J. The Cerebellum and Neurodevelopmental Disorders. Cerebellum. 2015 Aug 23.

40. Sultan, K.T., Shi, W., Shi, S.H. Clonal origins of neocortical interneurons. Current Opinion in Neurobiology. 2014, 26:125-131

41. Tan, S.S., Breen, S. Radial mosaicism and tangential cell dispersion both contribute to mouse neocortical development. Nature. 15 April 1993. 362(6421):638-40

42. Tantirigama, M.L.S., Oswald, M.J., Duynstee, C., Hughes, S.M., Empson, R.M. Expression of the Developmental transcription factor Fezf2 identifies a distinct subpopulation of layer 5 intratelencephalic-projection neurons in mature mouse motor cortex. The Journal of Neuroscience. 19 March 2014. 34(12):4303-4308

43. Weissman, T., Noctor, S.C., Clinton, B.K., Honig, L.S., Kriegstein, A.R. Neurogenic Radial Glial Cells in Reptile, Rodent and Human: from Mitosis to Migration. Cerebral Cortex. June 2003; 13:550-569

44. Xu, Q., Cobos, I., Cruz, E.D.L., Rubenstein, J.L.R., Anderson, S.A. Origins of Cortical Interneuron Subtypes. J of Neurosci. 17 March 2004. 24(11):2612-22

45. Young, K.M., Fogarty, M., Kessaris, N., Richardson, W.D. Subventricular zone stem cells are heterogenous with respect to their embryonic origins and neurogenic fates in the adult olfactory bulb. The Journal of Neuroscience. 1 August 2007. 27(31):82868296. 
46. Yu, Y.C., Bultje, R.S., Wang, X., Shi, S.H. Specific synapses develop preferentially among sister excitatory neurons in the neocortex. Vol 458, 26 March 2009. 501-505

47. Zimmer, C., Tiveron, M.C., Bodmer, R., Cremer, H. Dynamics of Cux2 expression suggests that an early pool of SVZ precursors is fated to become upper cortical layer neurons. Cereb Cortex. 2004. 14:1408-1420 